Portland State University

PDXScholar

7-11-1988

\title{
The Effectiveness of Fiction Versus Nonfiction in Teaching Reading to ESL Students
}

Becky Kay Appley

Portland State University

Follow this and additional works at: https://pdxscholar.library.pdx.edu/open_access_etds

Part of the Bilingual, Multilingual, and Multicultural Education Commons, and the English Language and Literature Commons

Let us know how access to this document benefits you.

\section{Recommended Citation}

Appley, Becky Kay, "The Effectiveness of Fiction Versus Nonfiction in Teaching Reading to ESL Students" (1988). Dissertations and Theses. Paper 3754.

https://doi.org/10.15760/etd.5639

This Thesis is brought to you for free and open access. It has been accepted for inclusion in Dissertations and Theses by an authorized administrator of PDXScholar. Please contact us if we can make this document more accessible: pdxscholar@pdx.edu. 
AN ABSTRACT OF THE THESIS OF Becky Kay Appley for the Master of Arts in English: TESOL presented July 11, 1988.

Title: The Effectiveness of Fiction Versus Nonfiction in Teaching Reading to ESL students.

APPROVED BY MEMBERS OF THE THESIS COMMITTEE:

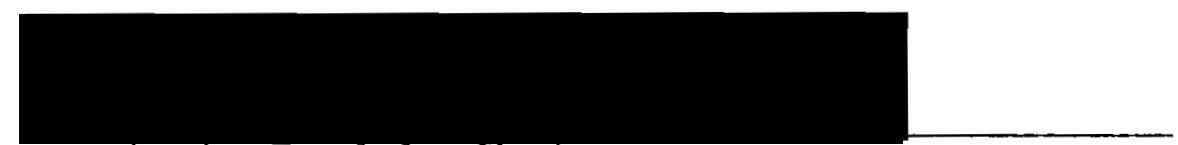

Marjorie Terdal, chairman
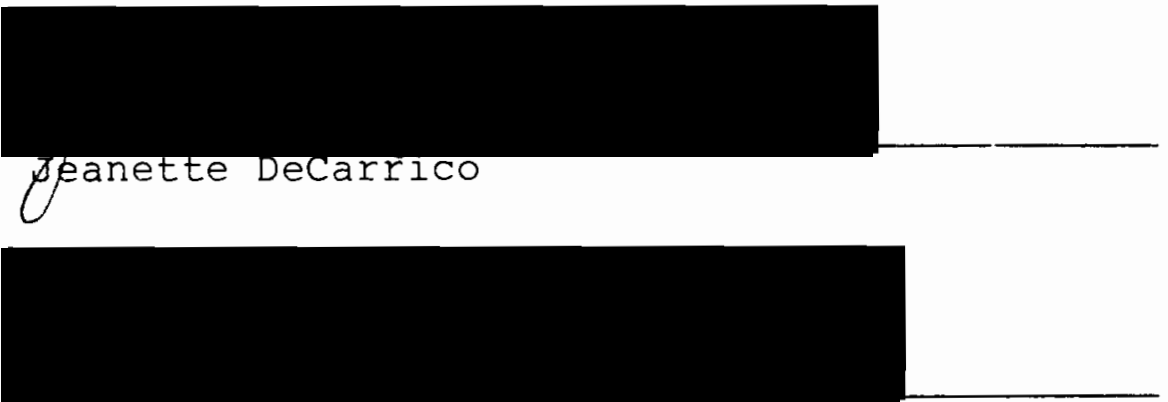

Shelley Reeple

Charles LeGuin

In recent years with the growing emphasis upon communicative activities in the classroom, controversy has risen as to which type of reading material is best for teaching reading in the ESL classroom, fiction or nonfiction. 
A study was conducted with 31 students of which 15 were taught with non-fiction and 16 were taught with fiction. Both groups were taught the same reading skills. Each group was given three pre-tests and three post-tests in which improvement in overall language proficiency and reading comprehension in the areas of main idea, direct statements and inferences was measured. Also, each group was observed for positive and negative behaviors during the fourth and eighth week of the study as well as responding to a questionnaire given the last week of the study which solicited their attitude toward the reading material used.

Four hypotheses were posed:

1. Students taught with literature, i.e. short stories, drama and poetry, and students taught with nonfiction will demonstrate no significant difference in overall langauge proficiency as shown by two cloze tests -- one using fiction and the other using nonfiction as the content.

2. Students taught with nonfiction will show greater increase in reading comprehension than students taught with literature, i.e. short stories, drama and poetry as measured by the Reading Comprehension Test by Descriptive Tests of Language Skills of the College Board.

3. Students taught with literature, i.e. short stories, drama and poetry, will demonstrate a more positive attitude towards reading than students taught with nonfiction as shown by a teacher's observations of class participation and students' behaviors.

4. Students taught with literature, i.e. short stories, drama and poetry, will demonstrate a more positive attitude towards reading than students taught with nonfiction as shown by a questionnaire.

In order to determine the outcome of this study, t-Tests 
were used with the cloze tests and the Reading Comprehension Test. No significant results occurred when the two groups were compared against each other although each group improved significantly from the beginning to the end of the study. In analyzing the observations, no conclusive trend could be determined as to which group displayed a more positive attitude. However, in regards to the questionnaire, the fiction group did display a slightly more positive attitude. 
THE EFFECTIVENESS OF FICTION VERSUS NONFICTION IN TEACHING READING TO ESL STUDENTS

by

BECKY KAY APPLEY

A thesis subinitted in partial fulfillment of the requirements for the degree of

MASTER OF ARTS in

ENGLISH: TESOL

PORTLAND STATE UNIVERSITY

1988 
TO THE OFFICE OF GRADUATE STUDIES:

The members of the Committee approve the thesis of Becky Kay Appley presented July 11, 1988.
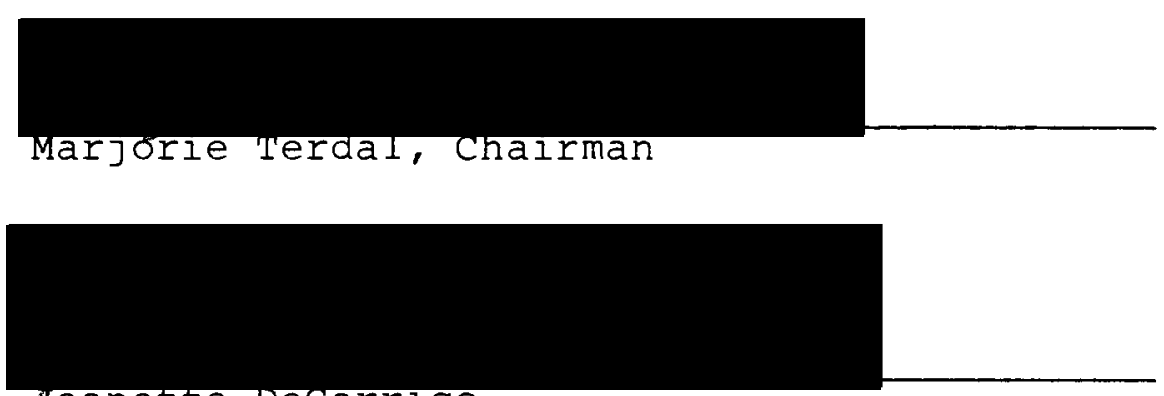
peanette Decarrico

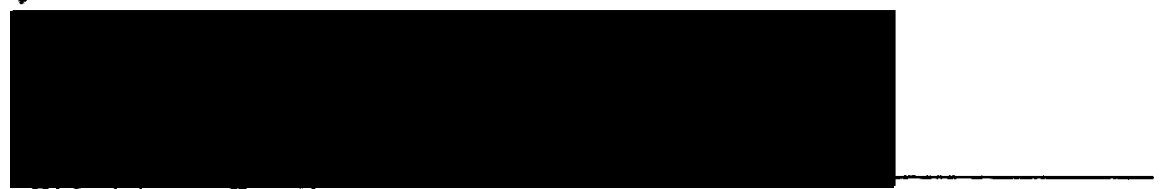
shelley Regfe

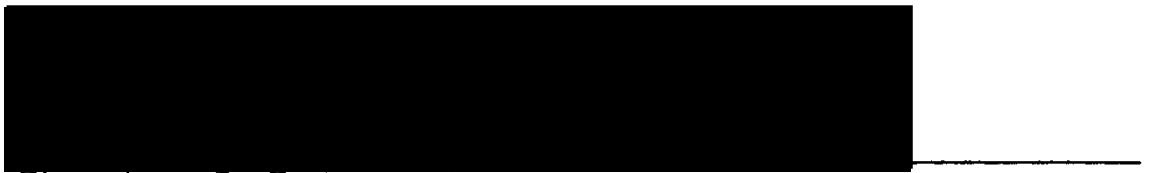

charles Leguin

APPROVED:
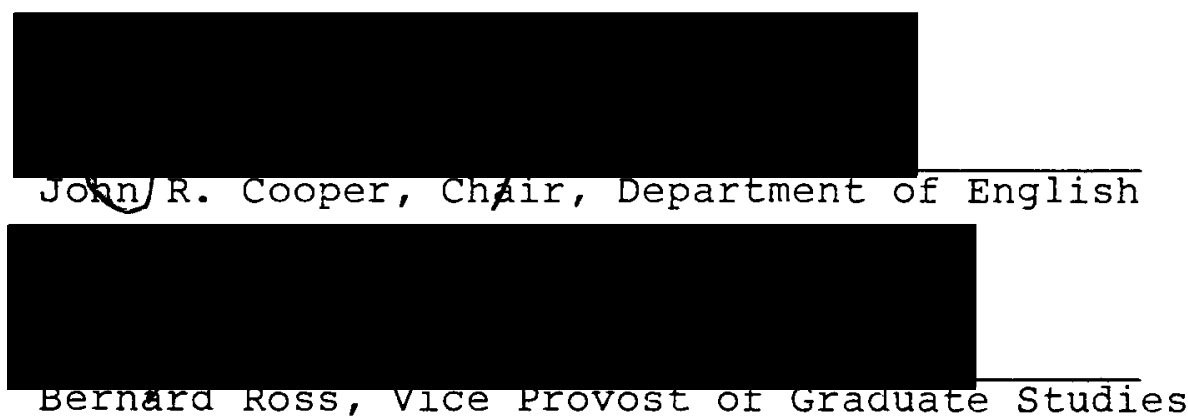


\section{ACKNOWLEDGEMENTS}

I would like to express my deepest gratitude to my friend and advisor, Dr. Marjorie Terdal. Without her constant encouragement and expert advise, this thesis would not have been completed. Also, Dr. Jeanette DeCarrico sparked my initial interest in this area and proviced me with very insightful ideas. Dr. Shelley Reece and Dr. Charles LeGuin also provided helpful ideas in the formulating and polishing of this thesis.

I would also like to extend my thanks to my mother, Mrs. Betty Appley, who with her continual support and encouragement was a constant strength throughout the entire research. Another source of encouragement and strength was my fiance, Mr. John Boesch.

But most of all, I want to express my thanks to God for His sustaining power throughout this entire time. He gave me the desire and the ability to achieve this goal and all praise and thanks goes to Him.

"For with God nothing is ever impossible."

Luke 1:37 
TABLE OF CONTENTS

PAGE

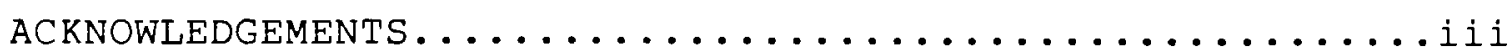

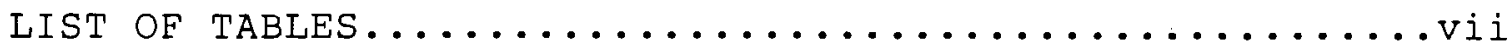

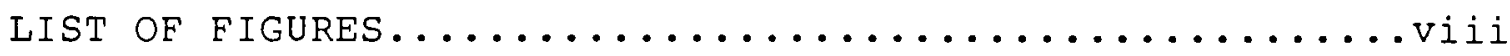

\section{CHAPTER}

I INTRODUCTION $\ldots \ldots \ldots \ldots \ldots \ldots \ldots \ldots \ldots \ldots \ldots$

Statement of Research Questions and

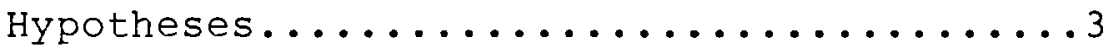

I I REVIEW OF THE LITERATURE................

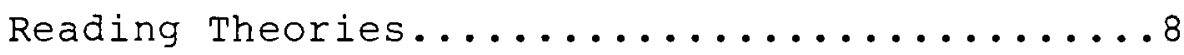

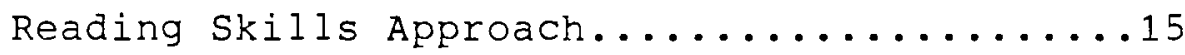

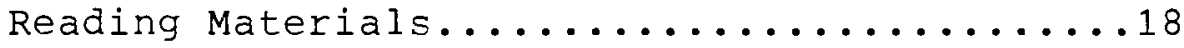

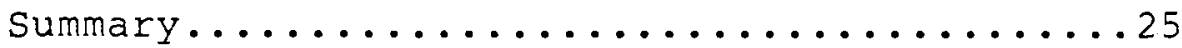

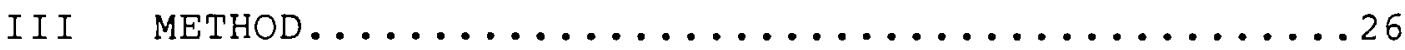

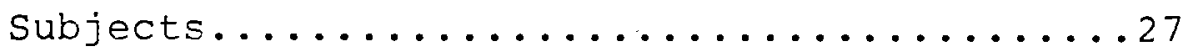

Research Design and Procedures............29

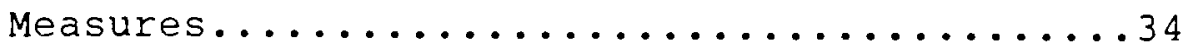

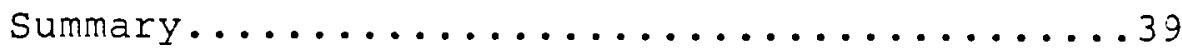

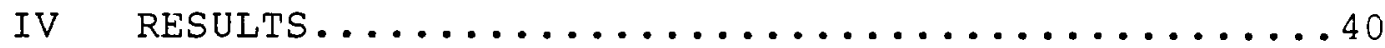

Results of Cloze Tests................40

Results of Reading Comprehension Test......42

Results of Classroom Observations.........44 
CHAPTER

PAGE

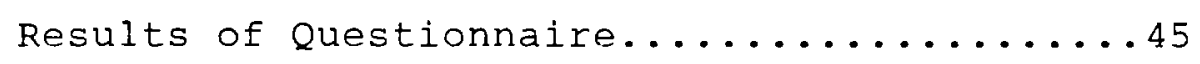

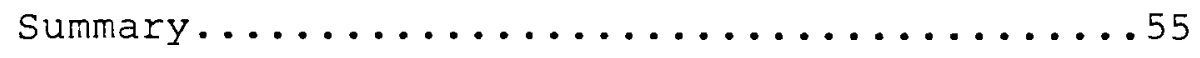

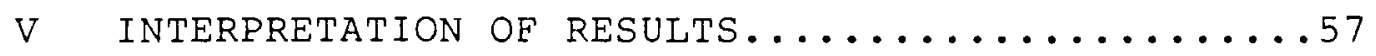

Interpretation of Cloze Test Results.......57

Interpretation of Reading Comprehension

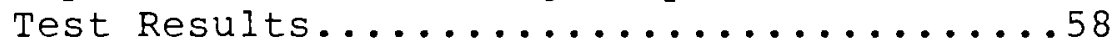

Interpretation of Classroom Observations....61

Interpretation of Reading Questionnaire.....63

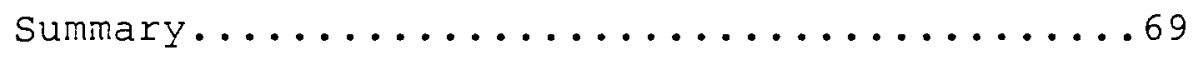

VI CONCLUSIONS AND RECOMMENDATIONS............71

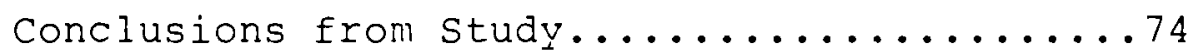

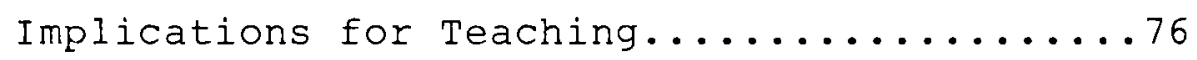

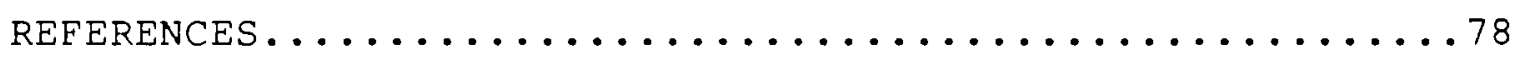

APPENDICES ............................... 81 


\section{LIST OF TABLES}

TABLE

PAGE

I Results of Cloze Tests with the Fiction Group....40

II Results of Cloze Tests with the Non-Fiction Group. 41

II Comparison of Cloze Test Results Between Groups...41

IV Results of Reading Comprehension Test with

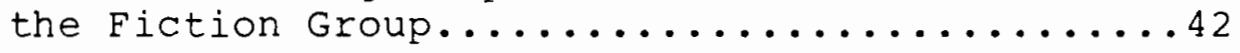

$\mathrm{V}$ Results of Reading Comprehension Test with

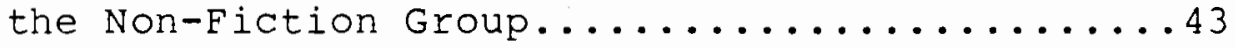

VI Comparison of Reading Comprehension Test Results

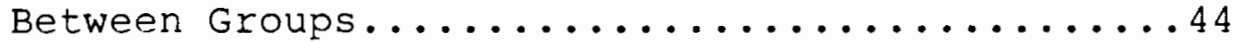


LIST OF FIGURES

FIGURE

PAGE

1. Observed Attitudes of Fiction Group at

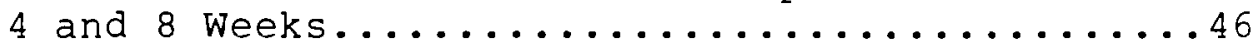

2. Observed Attitudes of Non-Fiction Group at

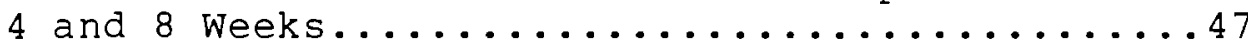

3. Comparison of Total observed Attitudes of

Fiction and Non-Fiction Groups..............48

4. Attitude of Fiction and Non-Fiction Groups Toward the Reading Material in regards to Enjoyment...550

5. Attitude of Fiction and Non-Fiction Groups Toward the Difficulty of the Language Syntax.........50

6. Attitude of Fiction and Non-Fiction Groups Toward the Helpfulness of Class Discussions..........51

7. Attitude of Fiction and Non-Fiction Groups Toward their Class Participation................51

8. Attitude of Fiction and Non-Fiction Groups Toward the Helpfulness of Reading Skills Taught......53

9. Attitude of Fiction and Non-Fiction Groups Toward the Future Relevance of the Reading Material...53

10. Attitude of Fiction and Non-Fiction Groups Toward the Reading Material's Ability to Develop

Critical Reading skills..................54

11. Attitude of Fiction and Non-Fiction Groups Toward the Reading Material's Ability to Teach

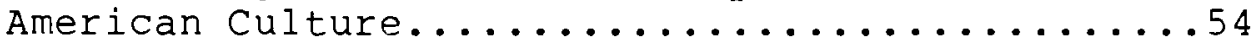

12. Attitude of Fiction and Non-Fiction Groups Toward How Much Their Vocabulary Increased..........56

13. Self Evaluation of Class Attendance by Fiction and Non-Fiction Groups.............56 


\section{CHAPTER ONE}

\section{INTRODUCTION}

Reading is one of the first skills a child learns in school. Traditionally, teachers have taught children to read by using fictional stories for several reasons. stories not only capture children's vivid imagination but also hold their interest. In addition, children's stories require very little background knowledge. This is important since children, due to their limited experience, possess very little background knowledge. However, when teaching adults, choosing the most suitable reading material becomes much more difficult. The need to cater to the imagination no longer plays as vital a role. And, because adults' interests vary much more and their background knowledge is so much greater, the choice of possible reading materials increases dramatically. This choice is further complicated when these adults are learners of English as a Second Language because different background knowledge and cultural understanding as well as unfamiliarity with language syntax must also be taken into account.

The consideration of these factors as well as the growing emphasis on communicative language has led recently to a renewed debate among ESL professionals as to which type 
of reading material is the best vehicle for use in teaching reading in the ESL classroom. For years most professionals have favored the use of nonfiction in the classroom in the belief that nonfiction reading selections draw upon the existing background of the ESL learner. In other words, nonfiction uses laws and principles which exist universally as in the subjects of science, math and business while avoiding culturally loaded ideas (usually found in literature) for which the learner has limited background knowledge. Advocates of nonfiction also state that the syntax of language found in nonfiction most closely resembles the language usea in society today while the language found in literature is often stilted and complex. This favoritism towards nonfiction, however, has been challenged recently with the move towards communicative language teaching. The focus in ESL classrooms has moved away from analyzing and dissecting the language to interacting and communicating with the language. Thus, because of this emphasis on communication in the classroom rather than just manipulation of language, teachers are opting for texts which produce authentic communication instead of those stilted textbooks developed especially for language teaching. In other worás, choosing texts which promote communication between the reader and what he/she is reading is the goal of a communicative language teacher. According to widdowson, a text is authentic only when the 
reader can interact with it causing genuine communication to take place (1979).

Because of this move toward an authentic language experience, using literature in the ESL reading class has gained new popularity. Those who endorse using fiction state that part of learning English as a Second Language is being able to interact with and understand the culture it represents. Literature is an excellent tool for allowing this communication to take place. Another major argument that those in favor of literature put forth is motivation. Because literature is enjoyable to read, students are motivated to read and this, in turn, enhances their reading skill. However, although both arguments appear valid, does either reading material - fiction or nonfiction - actually produce a greater positive effect on the student's language ability and motivation? This question leads to several hypotheses:

1) Students taught with literature, i.e. short stories, drama and poetry, and students taught with nonfiction will demonstrate no significant difference in overall language proficiency as shown by two cloze tests -- one using fiction and the other using nonfiction as the content.

2) Students taught with nonfiction will show a greater increase in reading comprehension than students taught with literature, i.e. short stories, drama and poetry as measurea 
by the Reading Comprehension Test by Descriptive Tests of Language skills of the college Board.

3) Students taught with literature, i.e. short stories, drama and poetry, will demonstrate a more positive attitude towards reading than students taught with nonfiction as shown by a teacher's observations of class participation and students' behaviors.

4) Students taught with literature, i.e. short stories, drama and poetry, will demonstrate a more positive attitude towards reading than students taught with nonfiction as shown by a questionnaire.

These hypotheses are based upon several assumptions. In the first hypothesis, it would seem that neither fiction nor nonfiction is any better at improving overall language proficiency so long as both types of materials are authentic. And, since the cloze tests use both nonfiction and fiction selections, they do not show bias towards either group of students. However, in the second hypothesis, those students taught using nonfiction should show a greater improvement in reading comprehension because the reading selections used in the Reading Comprehension Test are nonfiction thus favoring those who have read more nonfiction. On the other hand, both hypotheses three and four, according to popular opinion, should demonstrate that 
those students who are taught using literature have a better attitude and motivation towards reading than those taught with nonfiction.

Although the type of materials to use in the ESL classroom is under debate, the method for teaching those skills is well accepted in th ESL community. This method, called the reading skills approach, has developed from the psycholinguistic theory of reading. This theory states that reading is a four step mental process achieved through using three different types of cues. Reading is seen as an active process between the message encoded on the page and various cues the readers use to decode the message. The effectiveness of the readers' choice of cues determines the proficiency of their reading. Thus the reading skills approach teaches each of these various skills in isolation so that readers can become aware of the various stategies they are using to decode the message.

However, crucial to the comprehension of the passage is the knowledge the reader brings to it, which is referred to as background knowledge or schemata. This is simply to say that all the reader has ever experienced and learned in the past is the sum total of his/her background knowledge. For example, if readers with no training in economics attempt to read an advanced economics journal, they will have difficulty comprehending the text. Or, if they have very little knowledge about the syntax and structure of English 
and then attempt to read a structurally complex passage, they will again face difficulty in comprehending.

Although the reading skills method of teaching reading is generally accepted and can be incorporated with the trend toward communicative language teaching, the type of reading materials to use in conjunction with these is still in question. The following discussion will, perhaps, take the ESL community a step closer toward resolving the question of whether to use fiction or nonfiction in the ESL classroom. 


\section{CHAPTER TWO}

\section{REVIEW OF THE LITERATURE}

Several reading theories have developed through the years such as the phonics approach, the sight word approach and the linguistic approach. The current theory being used in ESL teaching is the psycholinguistic reading approach which, unlike the previous theories, focuses upon the mental processes involved in reading. By using a four-step process with the help of three types of cues the reader determines the meaning of a passage by using previously acquired knowledge or what is commonly called schema theory. This psycholinguistic reading theory is the basis of the reading skills approach, an approach that focuses upon teaching the specific mental processes involved in reading.

The acceptance of the psycholinguistic approach as well as the past emphasis on form and structure spurred the rejection of literature for nonfiction in the ESL classroom in the $60^{\prime} \mathrm{s}$ and $70^{\prime} \mathrm{s}$. Arguments such as complex syntax and culturally specific topics were put forth against literature. However, with the recent acceptance of communicative teaching, literature has gained a renewed popularity because it communicates authentic information. But now, the question facing the ESL community is 
determining which reading material, fiction or nonfiction, is most effective in the classroom.

\section{Reading Theories}

Teachers, whether they are aware of it or not, adhere to a particular theory of reading. This theory influences everything they do in the classroom. It determines what activities they use, what skills they teach and what reading selections they choose. Their outward actions in the classroom reflect their inward beliefs about reading. Or, as weaver states, a teacher's "instructional approach reflects a definition of reading, whether that definition is consciously formulated or implicit" (Weaver, 1980). Thus, in discussing the subject of reading, one must first look at various reading theories and their current popularity in ESL reading instruction today.

According to Weaver, three main views or theories of reading exist today. The first theory is what has been commonly called the phonics approach, of which Charles Fries was one of the main proponents. He proposed that reading was no more than the graphic representation of speech, as is reflected in the following statement by strickland.

The linguist conceives the reading act as that of turning the stimulus of the graphic shapes on a surface back into speech. The shapes represent speech; meaning is not found in the marks but in the speech which the marks represent (Weaver, $1980 \mathrm{p} \cdot 10$ ). 
Thus this theory states that once the words are converted into speech, then understanding will take place. According to Weaver, meaning lies in speech not in the words printed on the page. However, this theory does not explain, for example, the situation that exists in Japan today where many people read English much better than they can speak it. Yet if one were to adopt the phonics approach, a person could read only as well as he speaks. Thus, although the phonics approach is still used in first language (L1) learning, it has largely been rejected and is seldom used in ESI teaching today. The second theory, the sight word approach, although it does not recognize speech as essential in reading, still focuses upon the graphic representation on the page by proposing that once a student learns to recognize individual words he/she will master the art of reading. Similarly, the linguistic approach, originally proposed by skinner and based on his behaviorist theory of learning, also emphasizes word recognition but, instead of individual words, this theory focuses upon learning to recognize clumps of words (weaver, 1980). But this theory, like that of Fries, lost its credibility when Skinner's behaviorist theory came under attack in the $1960^{\prime}$ 's as a quote from Chomsky demonstrates.

Skinner takes experimental results and, by making analogic guesses, creates the illusion of a theory having scientific rigor and broad scope whereas, in fact, the descriptions of real life and of behavior in the laboratory are only vaguely similar (Athey, 1985, p. 43). 
Although these three theories offer different ideas as to what is the central component in learning to read, i.e. speech, individual words or clumps of words, they all see meaning as coming from a stimulus outside of the reader (Weaver, 1980). These theories fail to examine what occurs inside the reader during the process of reading. Thus when the psycholinguistic approach to reading was introduced, most reading theorists and teachers alike embraced it because it attempts to explain what occurs both inside and outside the reader during the process of reading. Today, the psycholinguistic theory of reading is generally accepted as the most suitable one among ESL professionals.

The psycholinguistic theory of reading refers to the process by which the reader reconstructs the message which has been graphically encoded on the page. Unlike the previous theories mentioned, reading is not just a reaction to the print on the page on the part of the reader but, according to widaowson, rather an interaction between the writer and the reader (Widdowson, 1979). Kenneth Goodman, a chief proponent of this theory, states that this interaction takes place through a four-step process. The reader

accomplishes this by sampling, relying on the redundancy of language, and his knowledge of linguistic constraints. He predicts the structures, tests them against the semantic context which he builas up from the situation and the ongoing discourse and then confirms or disconfirms as he processes further language (Goodman, 1973. p. 136). 
This is simply to say that readers read a certain portion of a text (sample) in which they selectively choose certain graphic cues depending on their knowledge of language. They then search their previous knowledge for matching syntactic, semantic and phonological clues. Based upon these clues, they make a guess (prediction) as to the meaning being conveyed. As they read further, they constantly check to see if their prediction was correct (test). If the following text confirms their earlier prediction they continue reading. If not, they jump back for more cues and make yet another prediction (Athey, 1985). According to Goodman,

Efficient reading does not result from
precise perception and identification
of all elements, but from skill in
selecting the fewest, most productive
cues necessary to produce guesses which
are right the first time
(Goodman, 1967, p.108).

As was alluded to previously, readers accomplish these various steps by using three types of cues -- graphophonic, syntactic and semantic -- simultaneously in the process of reacing (Goodman, 1973). According to Yetta Goodman, "the graphophonic system refers to the relationships between the sounds of language, and the written form of the language" (Goodman, p. 10, 1980). This one particular aspect of the psycholinguistic approach incorporates the basis for the phonics approach in that it recognizes the necessary link between written and spoken language. Readers rely on their 
oral competency to decipher the meaning of a written text. The second cue readers use is syntax, which "refers to the interrelationships of words, sentences and paragraphs" (Goodman, 1967). Kenneth Goodman specifically refers to function words and inflectional suffixes as examples of syntactic cues (Goodman, 1973). In other words, readers rely on their knowledge of grammar to understand the relationships in the text. Finally, and perhaps most important, readers rely on semantic cues, the actual meaning of the words. Knowing every word is not necessary for readers because based on the words they do know (context), they can guess the meaning of unfamiliar words. It is here that the reader's knowledge of the world comes into play. "The reader has available to him and brings to his reading the sum total of his experience and his language and thought development" (Goodman, p. 1967).

The idea that meaning is created and lies outside the graphic representation on the page is what sets the psycholinguistic theory apart from the other reading theories. The reader goes through a two fold procedure -process (comprehending) and product (comprehension) (clarke and Silberstein, 1977). Reading is not simply comprehension as the other theories suggest. Rather, reading is a process involving not only the language on the page but the thoughts and knowledge a particular reader brings to it. These thoughts and knowledge are often referrec to as background 
knowledge or schemata. Thus, within the psycholinguistic approach to reading, a theory known as schema theory has developed which refers specifically to the semantic aspect of psycholinguistic reading. The schema theory basically states that a reading selection is void of meaning but rather the meaning resides within the reader who uses his/her knowledge of the world to reconstruct and give shape to the text. This previously acquired knowledge is referred to as schemata (Carrell and Eisterhold, 1983). Rumelhart defines schemata as "building blocks of cognition" upon which all information processing depends. Within the reader, all knowledge is stored in units or schemata. Each schemata contains a prototype theory of a particular meaning (Rumelhart, 1980).

In all of this, it is useful to think of a schema as a kind of informal, private, unarticulated theory about the nature of the events, objects or situations that we face (Rumelhart, 1980, p.37).

Now having defined the meaning of schemata and given a basic understanding of what schemata actually is, the actual role of schema in reading can be examined.

During the process of reading two different types of information processing take place -- bottom-up and top-down. In this processing, "schemata are hierarchically organized from most general at the top to most specific at the bottom" (Carrell and Eisterhold, 1983, p. 557).

The data that are needed to instantiate or fill out the schemata become available 
through bottom-up processing; top-down processing facilitates their assimilation if they are anticipated or consistent with the...reader's conceptual set (Carrell, $1983, \mathrm{p} .82)$.

A very simple example will illustrate the use of schemata in bottom-up and top-down processing. The reader reads about a room. Immediately, top-down processing begins. He/she envisions the prototype of a room with one door and one window. However, at the same time, bottom-up processing is taking place. That is, the reading states the room has two doors and no windows. Consequently, the reader's prototype of a room (top-down) is slightly adjusted to fit the reality of the room in the reading (bottom-up). Thus, the reader has converged upon an acceptable understanding of the text.

Finally, although it will be discussed in depth later, it should be noted that in schema theory two different types of schemata exist: content and formal. Content schemata refers to the reader's knowledge about the content of the text whereas formal schemata refers to the reader's knowledge of rhetorical structures i.e. narrative, expository etc. If a reader lacks knowledge (does not possess the schematal in either the content area of a text or the formal structure, he/she will face difficulty in comprehending the text.

To summarize what has been discussed, it would be safe to state that the psycholinguistic approach is founded upon 
three major tenets. First, meaning is more important than precise identification of words. Second, efficient reading employs the use of all three language cues -- graphophonic, syntactic and semantic -- while relying less on graphophonic and more on semantic cues. And lastly, reading is an active search for meaning in which the reader him/herself brings meaning to the text (schema theory) (Weaver, 1980).

\section{Reading Skills Approach}

The acceptance of the psycholinguistic theory in ESL circles must also mean the application of it in the classroom. If one accepts Kenneth Goodman's basic premise that "reading requires not so much skills as strategies that make it possible to select the most productive cues" (Goodman, 1973, p. 139), then the focus as a teacher should be teaching these strategies. This is in agreement with Soule-Susbielles, who states that "reading competence would be greatly helped and speeded up if students were miade aware of what reading really is and what mental operations they should activate in order to become successful readers" (Soule-Susbielles, 1987, p. 198). In fact, Renee Vorhaus believes the strength students bring to the process of reading is their ability to think (Vorhaus, 1984). If this is true, then our goal as teachers is to apply the student's thinking ability to the various strategies involved in reading. The focus in teaching these skills should be "on 
the thinking processes involved with the goal of helping the student become consciously aware of the skill and how to monitor its use in getting meaning" (Mikulecky, 1984, p. 6). In fact, studies have shown that students who learn to become aware of their own reading processes become more skillful readers (Mikulecky, 1984). Therefore, in accordance with the psycholinguistic theory, it is our responsibility as ESL teachers to teach the various strategies and processes involved in reading. This teaching method is commonly called the reading skills approach.

The specific skills developed under this approach are generally divided, according to clarke and Silberstein, into two areas: reading skills and language skills. Reading skills include the four main areas of scanning (finding specific information), skimming (determining the general idea of a text), comprehension (gaining a thorough understanding) and critical reading (applying the information to one's own beliefs) (Clarke and Silberstein, 1977). Language skills generally work on such things as vocabulary, structure and discourse. Context clues and dictionary skills are taught under vocabulary. Structure is taught when the syntax is so complex that it causes problems in comprehension. And finally, discourse skills focus on such things as teaching rhetorical patterns i.e. narrative, description, cause and effect to name a few.

Barak Rosenshine, on the other hand, divides the skills 
taught in the reading skills approach differently. He classifies the skills into three general types which range in level of difficulty. However, these skills are based upon a "bottom-up" process of teaching reading which is not consistent with the schema theory. Therefore, clark and Silberstein's classification of skills is superior. Rosenshine labels the simplest skills as "locating details," which entail such skills as recognition, paraphrase and/or matching. The next step up in difficulty would be the "simple inferential skills" which are such skills as context clues and recognizing sequence of events, cause/effect and comparison/contrast. The last type and most difficult skills are the "complex inferential skills," which refer to the skills of recognizing main idea/title/topic, drawing conclusions and predicting outcomes (Rosenshine, 1980). Whether one classifies the skills under the categories Clark and Silberstein propose or those that Rosenshine proposes, there are certain skills which are necessary to teach if one adheres to the reading skills approach and the psycholinguistic theory of reading. Mikulecky gives a thorough list of those skills recognized under the reading skills approach. They are as follows:

1) previewing

2) predicting

3) questioning

4) scanning

5) recognizing the topic

6) stating the main ideas

7) guessing the meaning of words from context clues and word parts 
8) recognizing patterns of organization

9) using signal words

10) drawing inferences

11) visualizing, picturing or actually drawing a picture of what is described in the text

12) paraphrasing

13) using lexical clues to cohesion

14) skimming

15) critical reading

16) drawing conclusions

17) summarizing

18) reading faster

19) adjusting reading skills to suit a particular purpose. (Mikulecky, 1984, p. 5-6).

Barbara Isaacson and Gail Miller employed very similar skills to the ones Mikulecky has suggested in their teaching and found that their students actually improved in their reading comprehension skills by the end of the course. Their research further endorses the effectiveness of the reading skills approach and the validity of the theory behind it.

\section{Reading Materials}

The skills taught in the classroom are not the only concern of reading teachers. The materials used are also an important concern. Those that adhere to the reading skills approach encourage ESL teachers to choose texts "which would minimize the effect of the lack of knowledge" (Mikulecky, 1984, p. 4). Goodman himself states:

Reading materials in early language instruction should probably avoid special language uses such as literature and focus on mundane, situationally related language such as signs, directions, 
descriptions, transcribed conversations etc. (Goodman, 1973. p. 141).

Thus, proponents of Goodman's theory, upon his recommendation, have opted for reading materials that present uncomplicated and well-known subjects which require little cultural background knowledge, thus disqualifying the use of literature in the classroom.
As a consequence, literature teaching began to disappear from the 'language' classroom, to be replaced by a surrogate literature, commonly in the form of textbook dialogues and short tales, where learners were presented with the appearance of literature in the form of text devised to carry structure, but with none of the literary effect (Short and Candlin, 1986, p. 91).

Those who have interpreted Goodman's theory as requiring the exclusion of literature in teaching reading have offered some well accepted arguments. The first argument against the use of literature in the ESL class according to both Widdowson (1985) and McKay (1986) is that the main goal of ESL teachers is to teach the usual structure of language and since literature tends to use language in unique and complex ways, it is not appropriate in an ESL reading class. Second, McKay states that another argument presented is that literature will contribute nothing to the academic or occupational goals of the student.

And lastly and perhaps the strongest argument against literature is that it is too complex and too culturally 
biased for non-native readers to grasp. That is, ESL readers do not possess either the content or formal schema to be able to understand a literature selection. In regards to formal schema, Kintsch and Green (1978) believe that the simple story schemata of settings, beginnings, developments and endings is culturally specific to those who come from a European background. Thus, Kintsch and Green state that ESL learners may not have the schema for that particular rhetorical pattern in their background knowledge. Content schemata also poses a problem for the ESL reader. Although the validity of their experiment has been questioned, Steffensen, Joag-dev and Anderson (1979) found that Indian and American groups read faster and understood the naterial better when it dealt with something that was culturally familiar. These findings ana beliefs led Carrell and Eisterhold to state: "Reading comprehension involves one's knowledge of the world, which may be culturally based and culturally biased" (Carrell and Eisterhold, 1983, p. 555). Such conclusions simply reinforced the already existing negative attitude toward using literature in the ESL classroom.

How did this negative attitude toward using literature in ESL develop? The gulf that developed between English literature and English language occurred for two main reasons. From the period of 1960 through 1980, teachers unconsciously carried aspects of Goodman's theory to the 
extreme. They overemphasized the structural approaches to language learning. Classrooms concentrated on "discrete-point teaching, 'correctness' in grammatical form, and repetition of a range of graded structures, restricted lexis, etc." This teaching was unsuited to the use of literature (Long, 1986, p.43). While ESL classes were obsessed with the syntax and structure of language rather than the act of communication, literature teachers, too, forgot that their basis was also communication and literature classes were reduced to teaching about literature (i.e. movements of the time, author's background etc.) rather than teaching literature itself (Long, 1986). Another fact contributing to the disappearance of literature in the ESL classroom was the lack of consistent and effective teaching methods. Early in this century, literature in the ESL classroom centered around the classics, which tended to be much too difficult for non-native students to deal with initially. It was hoped that the sophisticated language in these texts would somehow influence the language of the ESI student (Short and Candlin, 1986). But no systematic method was used to teach the student the general reading processes involved let alone those specific ones necessary for reading literature. Unfortunately, this resulted in frustration on the part of both the student and the teacher and literature became unpopular in the ESI classroom. 
In the past, most ESL teachers have held this attitude toward literature while at the same time they have reduced the reading skills approach to the manipulation of skills and have ignored the equal focus it puts on meaning. For these reasons, until just recently, literature has remained outside the ESL classroom. But with the growing popularity of communicative language teaching, literature has begun to emerge once more in the ESL setting. Communicative language teachers believe that one should recognize that language is primarily a means of conveying information, ideas and attitudes rather than just a set of patterns to be manipulated (Widdowson, 1985). Thus literature is an ideal source for communication, as Hill demonstrates in her statement that "literature provides ... a genuine context for communication" (p. 9). Similarly, Collie and slater (1987) defend the use of literature in the ESL classroom because it provides "real" communication.
Literature offers a bountiful and ex- tremely varied body of written material which is 'important' in the sense that it says something about fundamental human issues, and which is enduring rather than ephemeral.... Literature is 'authentic' material. By that we simply mean that most works of literature are not fashioned for the specific purpose of teaching a language (Collie and Slater,1987, p. 3).

Because of the rise of this communicative approach in teaching, scholars have begun to refute the common arguments presented against literature. In the past, literature has been seen as different from language for the reasons stated 
earlier. However, short and Candlin (1986) propose that literature contains similar linguistic elements found in any other reading passage. They determined the number of linguistic elements through a series of experiments. One aspect they focused on was the stylistic analysis of other types of reading as opposed to literature. As had been proven earlier by Glaser with scientific literature, short and Candin found that there were not any linguistic features or set of linguistic features (specifically rhyme, metre, ambiguity, metaphor, parallelism anà linguistic deviation) found in literature that are not found in any other kind of text. The linguistic features only vary in number and concentration based upon the type of text being read.

Both Hill and collie and slater state that the language in literature is stilted, but they maintain that this lexical inappropriacy is not an insurmountable obstacle in teaching literature in the ESL classroom. It simply requires more thought and preparation on the part of the teacher. However, these authors give no specific evidence to support their ideas. Another argument against the use of literature is that it is too culturally specific. However, Mckay believes that students' "examination of a foreign culture through literature may increase their understanding of that culture and perhaps spur their own imaginative writing" (McKay, 1986, p.193). 
Not only can literature be an excellent introduction into the culture, but it can also serve as a source of motivation for the student. Motivation plays a key role in learning as both Short and Cantlin as well as McKay point out. According to Collie and slater, "Engaging imaginatively with literature enables learners to shift the focus of their attention beyond the more mechanical aspects of the foreign language system" (Collie and Slater, 1987, p. 5). Students will learn what they enjoy.

The main consensus among scholars seems to be that although literature should be used in the language classroom, it should be approached somewhat differently from other texts. According to Carter (1986) as well as Brumfit and Burke (1986), literature should be taught with two aspects in mind: language and the meaning found in that language. This seems very much in line with Goodman's original theory of reading. Those reading skills that focus upon understanding the structure of the language should be taught as a prerequisite to moving into more difficult skills such as drawing conclusions and making inferences. In other words, these beginning skills are stepping stones into understanding the essence of literature. "Responding to literature is not a matter of basic understanding of the language of the text. It is the significance of the text that is important" (Brumfit, 1986, p. 187). 
Summary

In conclusion, the use of literature has been a controversial issue in language teaching. For many years, it remained outside the ESI classroom because it did not fit the focus of language teaching at that time but with the swing towards communicative language teaching, literature has once again found its way into the ESL classroom. But, this time, ESL teachers have more insight into its use. BY spending time in preparation with the students as to its cultural specificity and complex language structure, these barriers can be overcome and the communicative aspect of literature can be employed. That is, meaning rather than structure can be taught.

However, even though literature has gained a new popularity in the ESI classrooom, little investigation has been done to test the assertions of its advocates. Likewise, nonfiction advocates have little scientific evidence to defend the use of nonfiction only in the classroom. Not only is there little research to support both these viewpoints but no one has attempted to determine which material -- nonfiction or fiction -- is more effective in the ESL classroom. Thus, the following study attempts to answer these questions by documenting the progress of students using nonfiction as opposed to fiction. Hopefully, this study will shed light upon which reading material is most suitable for ESL classes. 
CHAPTER THREE

METHOD

Thirty one students participated in a study in which sixteen were taught reading through fiction and fifteen were taught reading through nonfiction. Although all the students were undergraduates and similar in age, they differed in several areas namely nationality, skill level, amount of outside reading and length of time in the United states. Both groups were taught the same skills using the reading skills approach although some teaching techniques had to be modified slightly because of the different reading materials used. The literature selections consisted of poems, plays and short stories by predominantly twentieth century authors. The nonfiction selections came from a wide variety of magazines and textbooks. Due to the lower reading skill of the nonfiction group, their reading quantity during the study was smaller.

In order to determine the effectiveness of the different reading materials in regard to overall language proficiency and reading comprehension, three pre- and post-tests were given, two cloze and the Reading Comprehension Test. Also, a teacher's observations of students' behaviors in class helped determine the students' 
attitudes toward the reading material. And finally, a questionnaire which solicited students' attitudes towards various aspects of the reading material and study was administered the last week of the study.

\section{Subjects}

The study took place at two different colleges both located in Portland, Oregon. The number of undergraduate students involved in the study totalled thirty one. Sixteen were taught with fiction and fifteen were taught with nonfictionwith the researcher teaching both groups. The fiction group consisted of eight females and eight males who had resided in the united States for an average of five years. Most had attended American high schools. The nonfiction group was made up of nine females and six males who had been in the United States for an average of seven months. The fiction group displayed a wide range of nationalities: Iranian, Korean, Filipino, Cambodian, Laotian, Vietnamese, Eastern European, Ethiopian and Thai. On the other hand, the nonfiction group was fairly homogeneous with all Japanese students except two, one from Kuwait and the other from Cameroon. Although the length of time in the United States and nationalities differed from one group to the other, students in both groups were in their late teens and early twenties.

Academically, the groups also displayed differences. The students taught with fiction had a higher skill level 
than those taught with nonfiction since their acceptance level was $65-75$ on the Michigan Test of English Proficiency while the acceptance level for the nonfiction group was 50-65 on the same test. Yet although their acceptance levels demonstrated different skill levels, the class material that each of their academic programs required displayed the same difficulty level. Because the fiction group had lived in the United States for several years, their listening comprehension was better than those in the nonfiction group who had been here several months. The structure of the two academic programs that the students were enrolled in was quite different. The fiction group attended ESL class while, at the same time, attending regular academic classes such as psychology, biology etc. This ESL class combined the three skills of grammar, writing and reading for a total of six hours a week. Thus, each skill received a total of two hours per week of instruction. The nonfiction group, in contrast, attended ESL classes almost exclusively. The skills of reading, writing and structure, and conversation and listening were taught as separate classes with each class meeting approximately five hours a week.

Because the fiction group was enrolled in regular academic classes, their outside English reading was greater than the nonfiction group. The fiction group reported that they read English an average of 136 minutes outside class 
per day while the nonfiction group read English an average of 55 minutes. Similarly, the fiction group reported that they read more in their first language each day (84 minutes) than the nonfiction group (54 minutes). On the whole, the fiction group read almost twice as much as the nonfiction group.

Although these groups were incompatible in many areas, these areas were outside the control of the researcher. For example, the amount of instruction per week and difficulty of the reading material used in each class in accordance with their skill level was dictated by the administration of each of their academic programs. In addition, the fiction group was required to be taught fiction due to the academic program they were enrolled in.

\section{$\underline{\text { Research Design and Procedures }}$}

These students participated in a ten-week quasiexperimental design, a design necessitated because of the lack of random assignment to each group. The independent variable being tested in this study was the different materials administered to these two separate groups. Each group was taught the reading skills approach by the same teacher except that one group used strictly nonfiction while the other group used strictly literature, i.e. short stories, drama and poetry. As for the dependent variable, three pre- and post-tests were given in the first two weeks 
and the last week of class respectively. The tests employed were the Reading Comprehension Test and two cloze tests, one non-fiction and the other fiction. These tests were given in order to compare the effects of the treatment upon each group in overall language proficiency and reading comprehension. The third dependent variable, a teacher's observations, took place the fourth and eighth weeks of the study in order to document each student's participation and attitude. This was done so that the observations could be compared against each other in regards to attitude change within a class and attitude difference between the two classes. Finally, the fourth dependent measure was a questionnaire given the last week of the study to determine the students' attitudes toward the treatment they received in order to determine which type of reading material was enjoyed the most.

In conducting the research, each group was taught basically the same skills and the classes were structured as similarly as possible although, due to their academic programs, the fiction group received two hours of instruction a week while the nonfiction group received four hours. Those skills which both classes were taught are as follows:
1) previewing
2) predicting
3) scanning
4) skimming
5) topic
6) main idea 
7) context clues

8) patterns of organization

9) signal words

10) assumption

11) critical reading

12) drawing conclusions

13) summarizing

14) reading faster

15) fact/opinion

Because of the different reading materials used, the focus of some of these skills was slightly different in each

class. For example, whereas previewing with nonfiction also dealt with previewing subtitles and charts, those using fiction focused only upon titles. Also, within nonfiction there are several patterns of organization while fiction uses predominantly one. Those patterns of organization taught to the nonfiction group were narrative, description, comparison/contrast and cause/effect. On the other hand, those taught with fiction learned predominantly the narrative pattern although within this pattern there are elements of description, comparison/contrast and cause/effect. Thus, the fiction group became acquainted with these different patterns, but it was possible to present them as a separate type of rhetorical organization. Because of this, in presenting signal words, the nonfiction group learned the appropriate signal words for each pattern of organization while the fiction group learned signal words as separate from any particular type of rhetorical organization.

Also, for several reasons, the classes were structured 
slightly differently. The reading quantity of the literature group was greater because of their higher skill level and because the reading selections were longer. Also, because the class had no textbook which taught these skills in isolation first, these skills were taken from the reading selections themselves. (See Appendix A for a sample of fiction lesson plans). Therefore, in most cases (except previewing, skimming and scanning) it was absolutely necessary for these students to read these selections before class. Thus, weekly quizzes were often given to provide incentive for reading selections before coming to class. The nonfiction class was structured differently because they had a textbook which taught these reading skills separately and then applied them to paragraphs rather than long reading selections. In order to compensate for the lack of reading quantity, a longer reading selection was assigned each week from various sources.

The material used in the fiction class consisted of four poems, two plays and twelve short stories. Most of the reading selections came from twentieth century American and British authors because the syntax and vocabulary were considered less difficult to understand than earlier American and British writers. Some of the authors used were William Saroyan, James Thurber, John Steinbeck, Jack London, Robert Frost, Richard Wright, Sherwood Anderson and D.H. Lawrence. The selections averaged about six pages in length 
and were organized around the following themes: 1) man versus nature 2) the battle of the emotions 3) growing up 4) facing death 5) defining insanity 6) racial conflict 7) work 8) struggle with identity. These selections were compiled in a 171-page packet. (See Appendix B for the table of contents of this packet).

The material used in the nonfiction class was mainly found in the textbook, Reading and Study Skills: A Rhetorical Approach by Kimmelman, Krantz, Martin and seltzer. The text was divided into three parts: comprehension skills, study skills and vocabulary skills. The comprehension skills section dealt with the four rhetorical patterns mentioned above and within this discussion such skills as signal words, prediction, assumptions and fact/opinion. The second section, study skills, dealt with previewing, topics, main ideas and supporting details. The last section addressed using context clues to determine vocabulary. The authors used nonfiction material (some authentic) by moving from sentences to paragraphs to longer selections with each skill taught. (See Appendix $\mathrm{C}$ for the textbook's table of contents). To quote the authors themselves:

We believe that these students can work most effectively when they learn skilis presented in a logical and sequentially developed manner, first acquiring skilis presented through short, easy material and then applying the skills in more difficult passages ( $p$. ix). 
In addition to the textbook, the students read nine different selections averaging three pages in length. These selections were taken from such sources as Newsweek, Fortune magazine, U.S. News and world Report, and psychology, linguistics and anthropology texts of which all were authentic material. They contained such themes as second language acquisition, dating, the American male identity, parental love, culture shock, the job market and male and female biological differences. (See Appendix D for discussion questions from the above articles). In addition, both fiction and nonfiction classes read longer selections outside of class and wrote a summary of what they read. Each student in the fiction class chose several short stories which averaged about thirty pages while the nonfiction class chose a Newsweek article of their choice, which averaged about six pages.

\section{Measures}

It is necessary to examine the specific measures used to test the progress of the two groups. The first measures used were two cloze tests which test overall language proficiency. These criterion-referenced tests were fill-in-the-blank tests in which every seventh word was deleted from a reading selection of approximately 375 words. The student needed to fill in the blank with an appropriate word in meaning and syntax. Each student was given twenty 
five minutes to complete the test. The construct validity of these texts was based upon the necessity to master three skills for reading comprehension: 1) meanings found in lexical items 2) meanings found in syntax and 3 ) socio-cultural meanings (Aitken, p. 62). Or to state it differently,

readers must perceive words, phrases and sentences in print; must have experiences which provide a basis for understanding these words, phrases and sentences; must grasp meanings that are greater than words themselves; and must use this control of print in many different ways (Aitken, p. 62)

In choosing reading passages to convert into a cloze, several things were taken into account with regard to content validity. The nonfiction pre- and post-tests were two modern fairy tales which were almost identical to each other. They both followed the typical narrative rhetorical pattern of fiction and contained fundamental concepts of American culture. (See Appendix E for a sample of these tests). The nonfiction cloze test used a selection from Newsweek which totalled approximately 750 words. Since the nonfiction group read several similar articles during their treatment, they became familiar with the structure of this type of article. The first half of the selection was given as the pre-test and the second half was given as the post-test. Because the post-test began in the middle of the article a large amount of context was supplied before the students were required to fill in the blanks. (See Appendix 
F for a sample of these tests). By giving two cloze tests, one using nonfiction and the other using literature, bias towards either group was reduced. Also, the vocabulary and syntax of each selection was considered comparable to the subjects' level although this was difficult because of the different skills level of the two groups. The cloze test has also been shown to be reliable by Darnell who found a high correlation (.83) with the TOEFL test (Aitken, p. 59).

The second instrument used, which is norm-referenced, is the Reading Comprehension Test developed by Descriptive Tests of Language Skills of College Board. It consists of 45 questions which test three reading skills: 1)

understanding main ideas, 2) understanding direct statements, 3) drawing inferences. The test includes 15 short nonfiction reading passages each followed by several questions. According to the manual of Descriptive Tests of Language Skills, the construct validity is based upon the idea that reading comprehension depends upon a student's ability to understand main ideas and direct statements and from these draw correct inferences. The types of questions employed are commonly used in the measurement of language skills and thus "there is considerable evidence that performance on such questions does provide sound indications of aspects of students' reading...abilities" thus endorsing the test's content validity (p. 44). The Reading Comprehension Test also shows a reliability coefficient of 
.89 which gives an indication of the level of correlation that would be expected between the scores obtained by a group of two different forms of the test and a standard error of measurement of 1.8 .

The third measure was a teacher's observations of specific student behaviors in the classroom using a variation of an at-task coding scheme. The observer was given a form with each student's name listed. Every two minutes during the class, the observer documented with codes what each student was doing in regards to active and passive behavior in the classroom. The specific actions which the teacher documented were: 1) eye contact with the teacher 2) eyes downcast or wandering 3) sitting erect 4) sitting slouched 5) talking on task 6) talking off task 7) reading 8) writing. Those actions which which were considered to display a positive attitude or active behavior were numbers one, three, five, seven and eight. Conversely, those numbers which were considered to display a passive or negative attitude were numbers two, four and six. (See Appendix $G$ for a sample questionnaire). Based on the students' participation and attitude in class, the effectiveness of the teaching materials could be determined. The same teacher did all four observations so that the results would be consistent.

Finally, the last measure used was a questionnaire administered to the students in order to determine their 
attitude toward the materials used in class i.e. nonfiction or literature. The questionnaire consisted of ten questions in which the students responded on a scale of one to five, one representing "no, not at all" and five representing "yes, very much" except for the last question, which asked the percentage of their attendance in class. Each question addressed the the main points of argument between using fiction or nonfiction in the classroom as well as measured the students' attitudes. The first question addressed the students' attitude toward the reading materials. The second question determined if the students found the syntax of the language in the reading selections difficult since this has been a major argument presented against literature. The third question attempted to determine attitude towards the class discussions while the fourth question solicited the amount to which the students participated in these discussions. Question five measured attitude towards the actual skills taught thus evaluating attitude toward the reading skills approach. The sixth question addressed the argument that literature is not relevant for the students' future academic careers. The seventh question tried to determine if the students believed they had learned critical reading skills since literature advocates state that literature forces the students to develop their abstract thinking skills. Literature advocates also state that literature is an excellent source for teaching culture, so 
the students thought their vocabulary had increased. And finally, the tenth question had the students circle their class attendance anywhere from seventy to one hundred percent.

\section{Summary}

This research was conducted with the hope of answering some of the questions being debated over using fiction or nonfiction in the classroom. Even though there were undeniable differences between the two groups, the research was undertaken to shed some light upon the effectiveness of literature versus nonfiction in the classroom in regards to overall language proficiency, reading comprehension and attitude. 


\section{CHAPTER FOUR}

\section{RESULTS}

In this chapter the results of the various measures used during the the research are reported: the results of the cloze tests, reading comprehension test, classroom observations and questionnaire.

Results of Cloze Tests

One-tailed paired t-Tests were used to analyze the improvement in overall language proficiency as measured by the two cloze tests. Both groups demonstrated a significant improvement at .05 from the pre-test to the post-test on both the nonfiction and fiction cloze tests. The fiction group showed a significant improvement in the nonfiction and fiction cloze tests with a mean of the differences of 0.05392 and 0.22896 respectively as shown in Table 1 .

\section{TABLE I}

RESULTS OF CLOLE TESTS WITH THE FICTION GROUP

\begin{tabular}{lcc}
\hline & Fiction & Non-fiction \\
\hline Probability Level & $0 *$ & $.02775^{*}$ \\
Mean of Differences & .22896 & .05392 \\
Note: * = significant results at .05 significance level
\end{tabular}


The nonfiction group demonstrated a significant improvement on both cloze tests as well with a mean of the differences of 0.11373 on the fiction cloze and 0.28687 on the nonfiction cloze as referred to in the following table.

TABLE II

RESULTS CF CLOLI TESTS WITH THE NON-FICTION GRCUY

\begin{tabular}{lcc}
\hline & Flction & Non-fiction \\
\hline Probability Level & $.00001^{*}$ & $.00831 *$ \\
Mean of Differences & .28687 & .11373 \\
Note: * = significant results at .05 significance level
\end{tabular}

However, in examining the improvement between the two groups in overall language proficiency, no significant results were found. As noted in Table 3, a two-tailed two sample t-Test of equal variance revealed a pooled variance of 0.01823 in regards to the nonfiction cloze test and 0.02303 in regards to the fiction cloze test.

TABLE III

COMPARISON OF CLOZE TEST RESULTS BETWEEN GROUPS

\section{Fiction}

Probability Level

Pooled Variance
.29700

.02303

\section{Non-fiction}

.22774

.01823 
Thus, in regards to the cloze tests, significant improvement was found from the pre-test to the post-test in both groups, but when the two groups were compared against each other, no one group improved significantly over the other.

Results of Reading Comprehension Test

In regards to the Reading Comprehension test, again both the fiction and nonfiction groups demonstrated a significant improvement at .05 in overall reading comprehension from the pre-test to the post-test as shown by one-tailed paired t-Tests. As can be seen in Table 4, the fiction group revealed a mean of the differences of 4.62500 while the nonfiction group in Table 5 revealed a mean of the differences of 3.33333 .

TABLE IV

RESULTS OF READING COMPREHENSION TEST WITH THE FICTION GROUP

\begin{tabular}{lcccc}
\hline & Overall & Main Idea & Direct Statements & Inferences \\
\hline $\begin{array}{l}\text { Probability Level } \\
\text { Mean of }\end{array}$ & $.02112^{*}$ & .30232 & $.04011^{*}$ & $.00878^{*}$ \\
Differences & 4.62500 & .68750 & 1.31250 & 2.31250 \\
Note: * = signiflcant results at .05 significance level &
\end{tabular}


TABLE $V$

KESULTS OF READING COMPREHENSION TEST WITH THE NON-FICTION GROUP

Overall Main Idea Direct Statements Inferences

$\begin{array}{lcccc}\text { Probability Level } & .01498 * & .00783 * & .13184 & .02802 * \\ \begin{array}{l}\text { Mean of } \\ \text { Differences }\end{array} & 3.33333 & 1.33333 & 0.46667 & 1.53333\end{array}$

Note: * = significant results at .05 significance level

Within the Reading Comprehension Test, three different types of questions were employed to measure comprehension of main ideas, direct statements and inferences. A paired t-Test was used with both the fiction and nonfiction groups to determine their improvement from the pre- to post-tests in each of these areas as Tables 4 and 5 illustrate. The fiction group did not show a significant improvement in main ideas with a mean of the differences of 0.68750 . However, the fiction group did demonstrate a significant improvement in comprehending direct statements and inferences with a mean of the difference of 1.31240 and 2.31250 respectively. Conversely, the nonfiction group showed a significant improvement in the areas of comprehending main ideas and inferences while the group did not reveal a significant improvement with direct statements. The mean of the differences with the main idea was 1.33333 with the mean of the differences of inferences at 1.53333. The direct 
statements did not show any significant improvement with a mean of the differences of 0.46667 .

To determine if there was any significant difference in improvement between the nonfiction and fiction groups, a one-tailed two sample $t$-Test of equal variance was employed in the areas of main idea, direct statement, inferences, and overall reading comprehension. In these four t-Tests no significant difference. in improvement between the two groups was found. (See Table 6). The pooled variance was 5.13003 for main ideas, 5.21279 for direct statements, 8.79899 for inferences and 36.37141 for overall reading comprehension.

\section{TABIE VI}

COMPARISON OF REAUING COMPREHENSION TEST RESULTS BETWEEN GROUPS

\begin{tabular}{lcccc}
\hline & Overall & Main Idea & Direct Statements & Inferences \\
\hline Probability Level & .53698 & .43398 & .31114 & .47070 \\
Pooled Variance & 36.37141 & 5.13003 & 5.21279 & 8.79899
\end{tabular}

Results of Classroom Observations

The observed classroom behaviors consisted of eight behaviors, five of which showed a positive attitude -- eye contact, sitting erect, talking on task, reading, and writing -- and three of which indicated negative attitude -- 
eyes downcast and wandering, sitting slouched, and talking off task. In regards to the observed positive or negative attitude classroom behaviors, the fiction group from the four to eight week observations the frequency of all the observed behaviors increased except talking off task, which remained the same. (See Figure 1). The nonfiction group, on the other hand, between the fourth and eighth week, showed a decrease in the behaviors of eye contact, eyes downcast and wandering and writing while showing an increase in talking on task, talking off task and reading. (See Figure 2). When the fourth and eighth week observations were combined in each group and then compared against each other, the fiction group showed slightly higher frequencies of eye contact, sitting erect, sitting slouched, talking on task and talking off task while the nonfiction group displayed higher frequencies of eyes downcast and wandering, reading and writing. (See Figure 3 ). It should be noted that the fiction group possessed one more student than the nonfiction group.

\section{Results of Questionnaire}

Again, the different number of responses in each group needs to be taken into account. The fiction group consisted of 16 while the nonfiction group consisted of 14 responses. (One student was absent when the questionnaire was given). The students responded to each question based on a five 


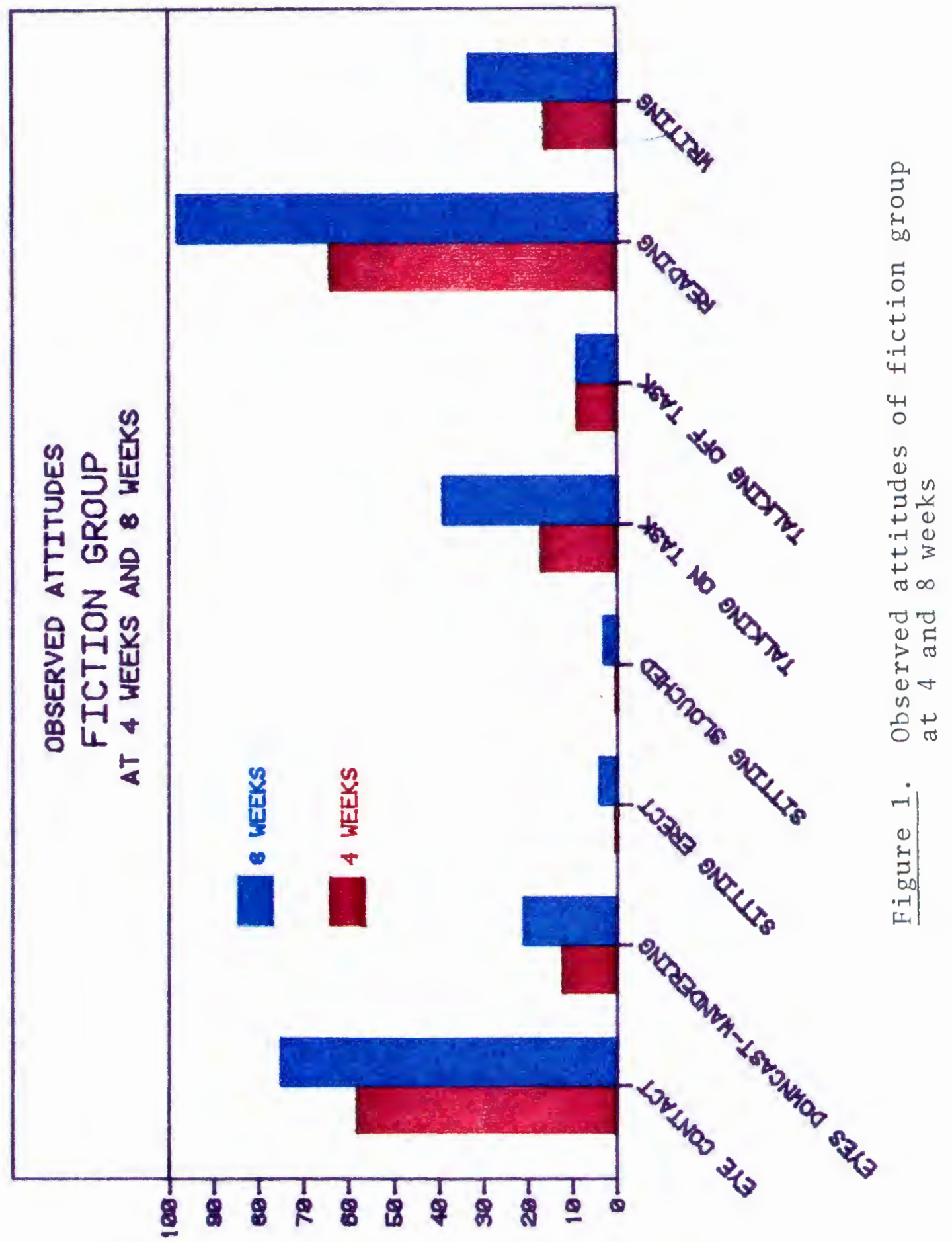

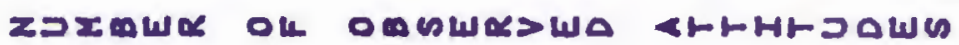




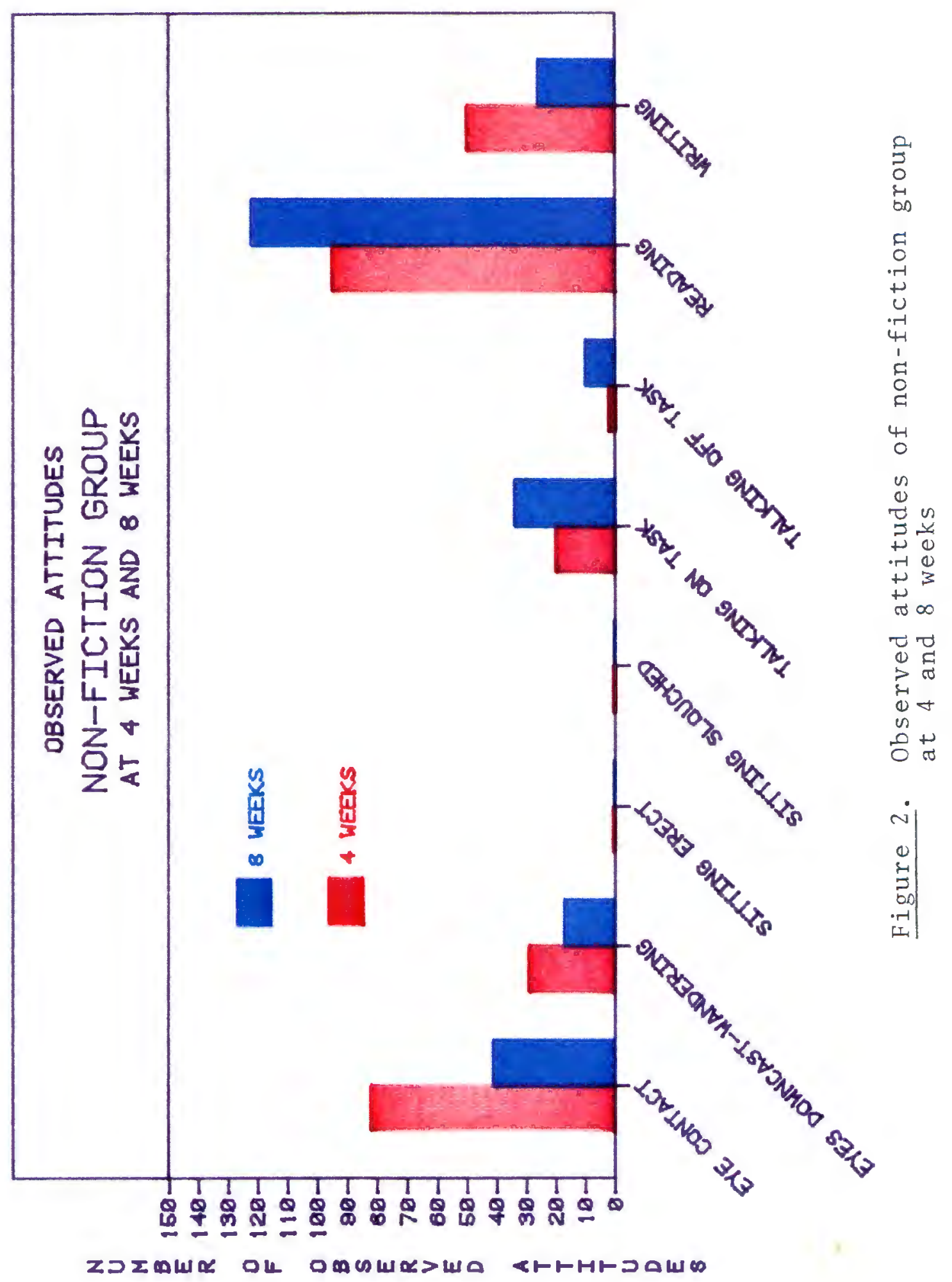




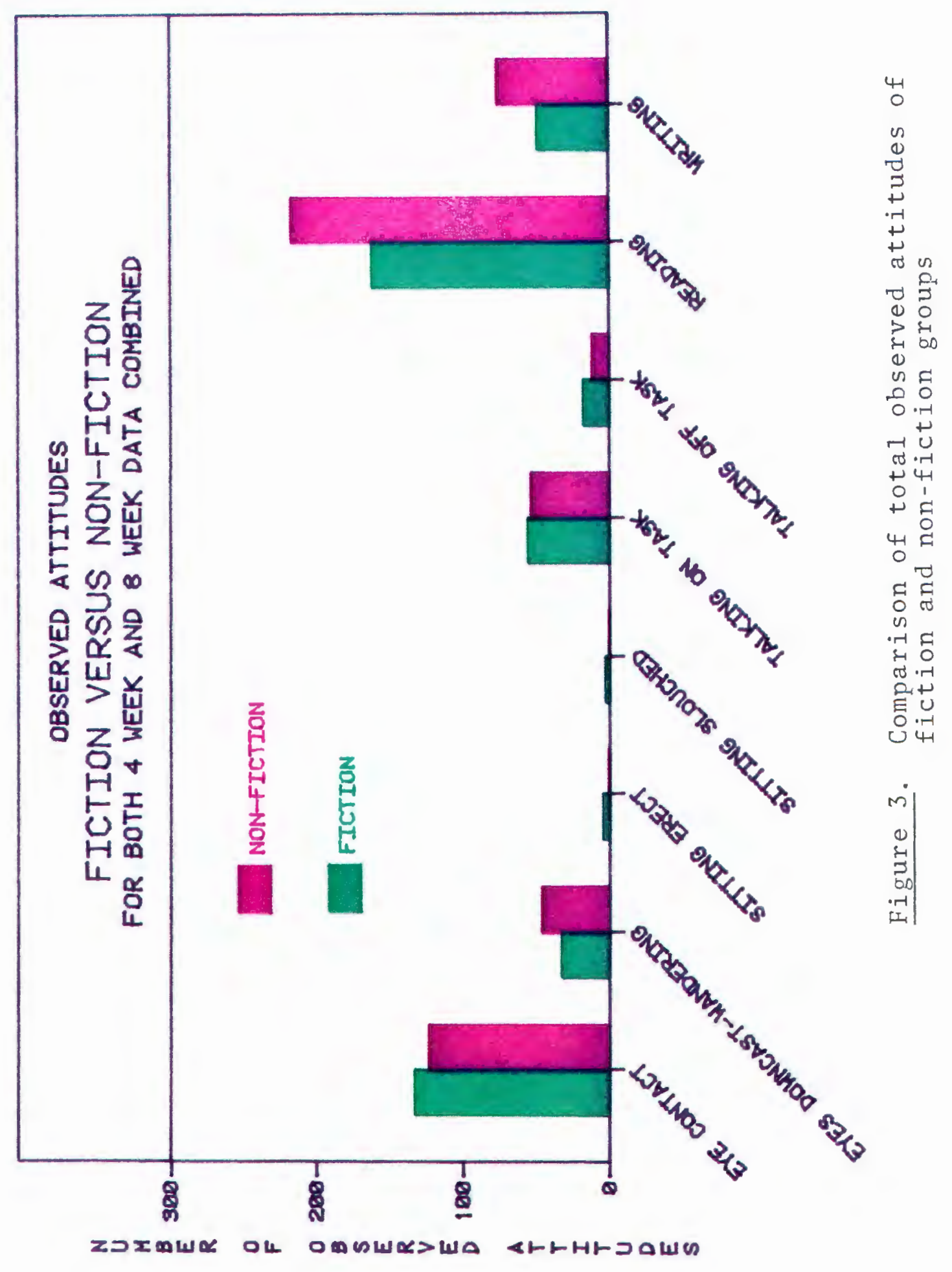


point scale from "no, not at all" to "yes, very much." In order to tabulate the mean of each of these questions, each response was given a numerical value with "no, not at all" worth the lowest value of one point and "yes, very much" worth the highest value of five points. The first question of the questionnaire addressed how enjoyable the students found the reading material with five points representing the highest level of enjoyment. The fiction group had a mean of 4.0625 while the nonfiction group mean was 3.857 . (See Figure 4 for the individual distribution of these responses.)

The second question addressed the difficulty of the language syntax used in each reading selection. Both groups found the language syntax "somewhat" difficult with the mean of the fiction group at 3.25 and the mean of the nonfiction group at 3.57 . (See Figure 5). The third question measured if the students felt the class discussions were helpful. The means of both groups fell within the "yes" response with the mean of the fiction group at 4.5 and the mean of the nonfiction group at 4.14. (See Figure 6). Question four revealed the students' self evaluation of the degree to which they had participated in these class discussions. The mean of the fiction group (4.75), indicates that they felt that "yes" they had participated a great deal in class discussions while the mean of the nonfiction group (3.43) revealed that they felt they had "somewhat" participated in 


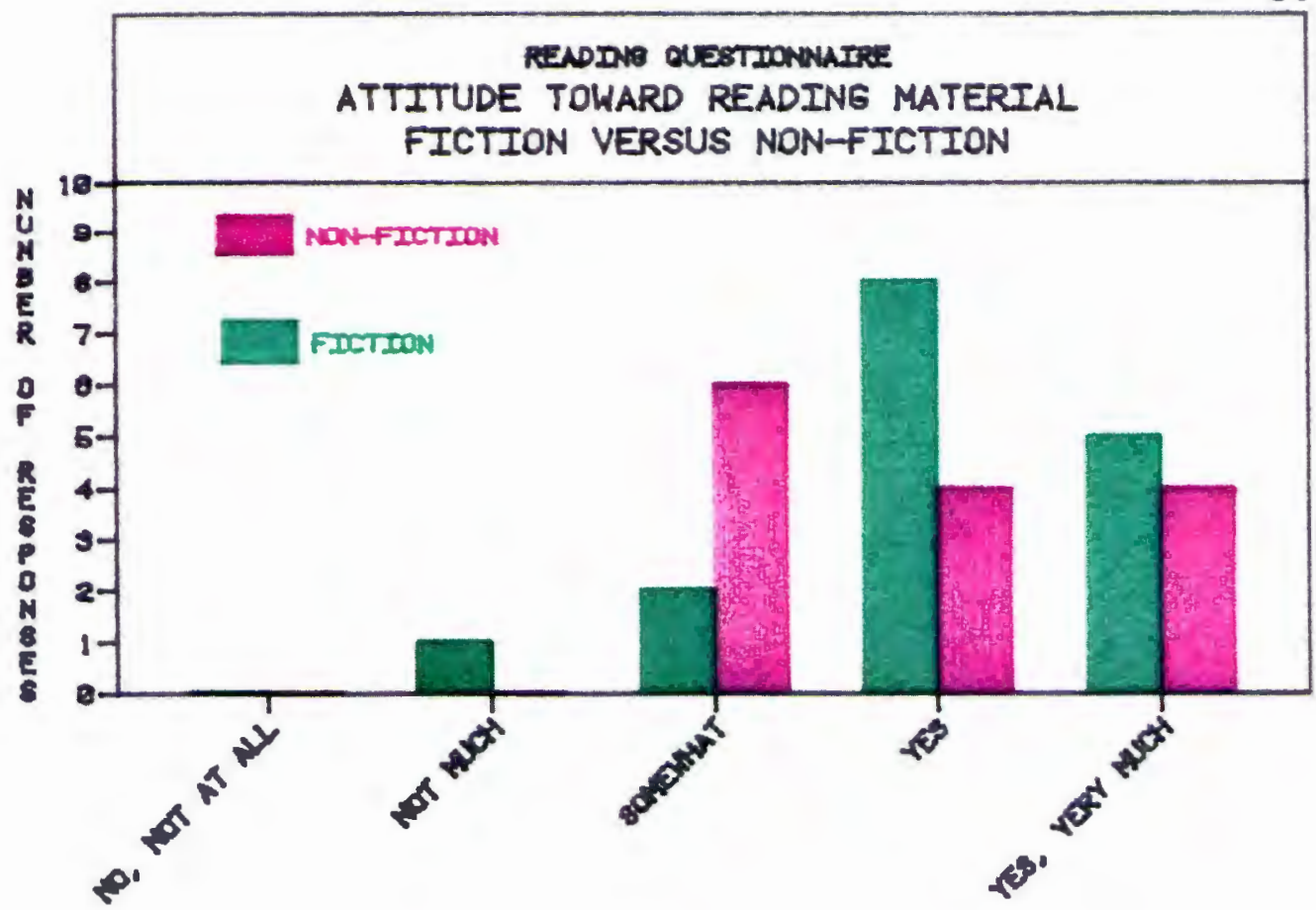

Figure 4. Attitude of fiction and non-

fiction groups toward the reading material

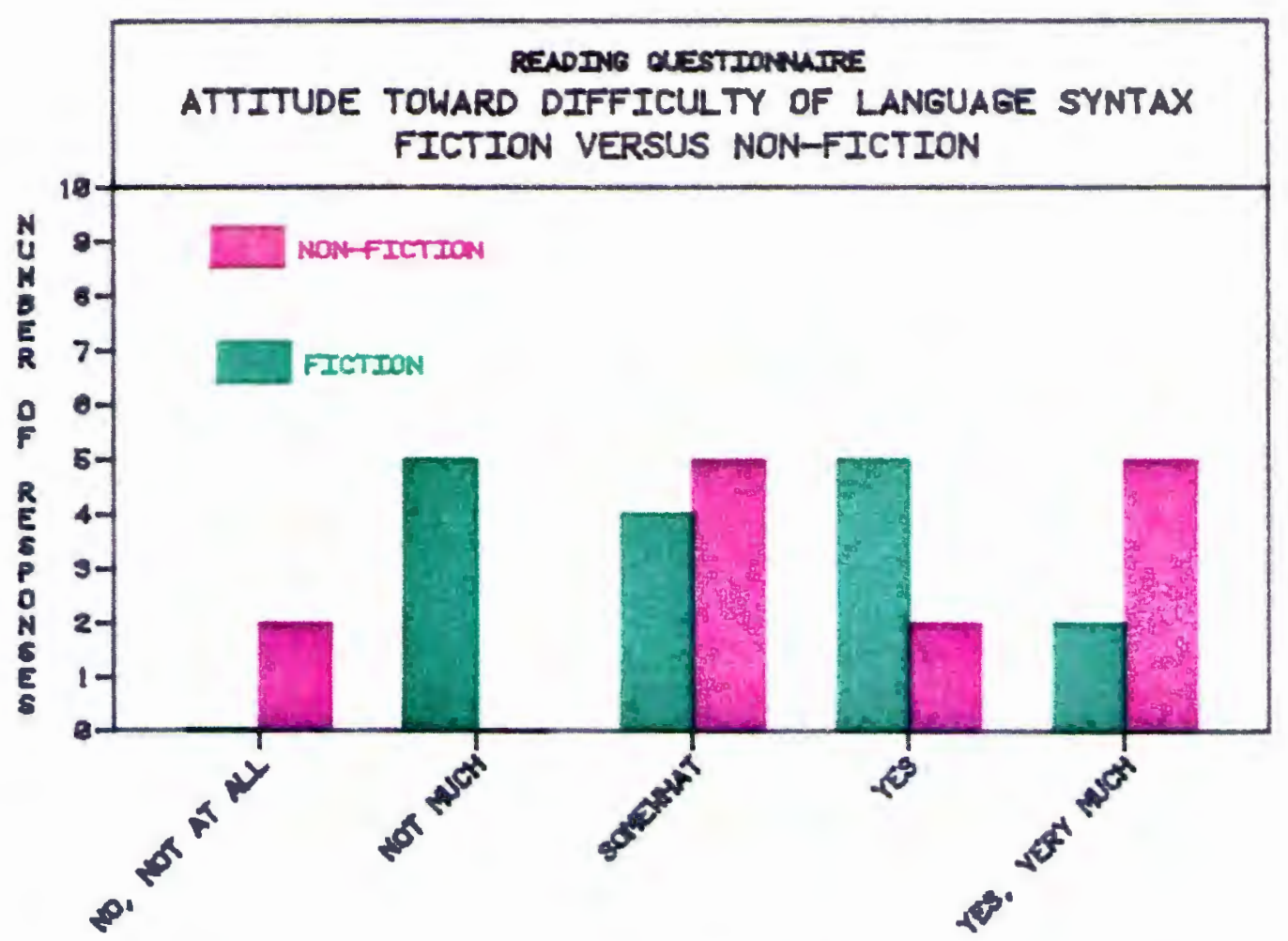

Figure 5. Attitude of fiction and nonfiction groups toward the difficulty of language syntax 


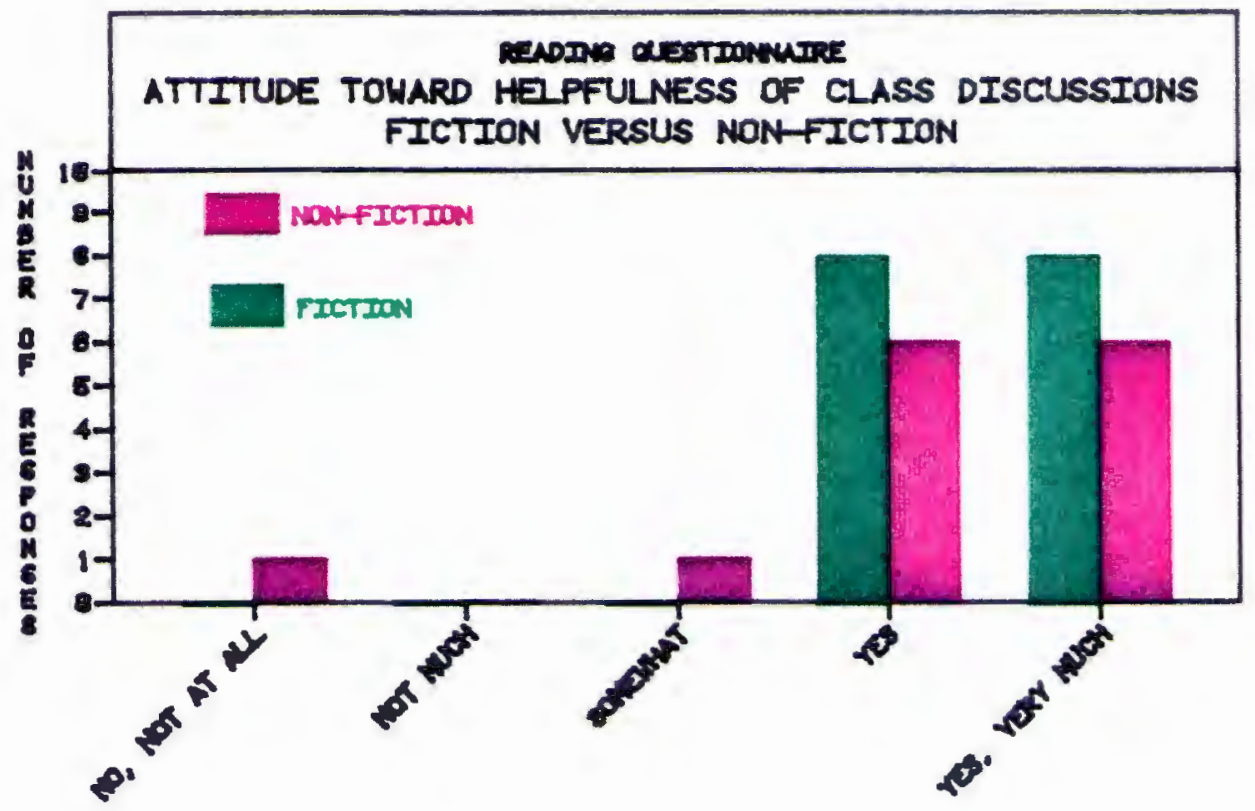

Figure 6. Attitude of fiction and non-

fiction groups toward the helpfulness

of class discussions

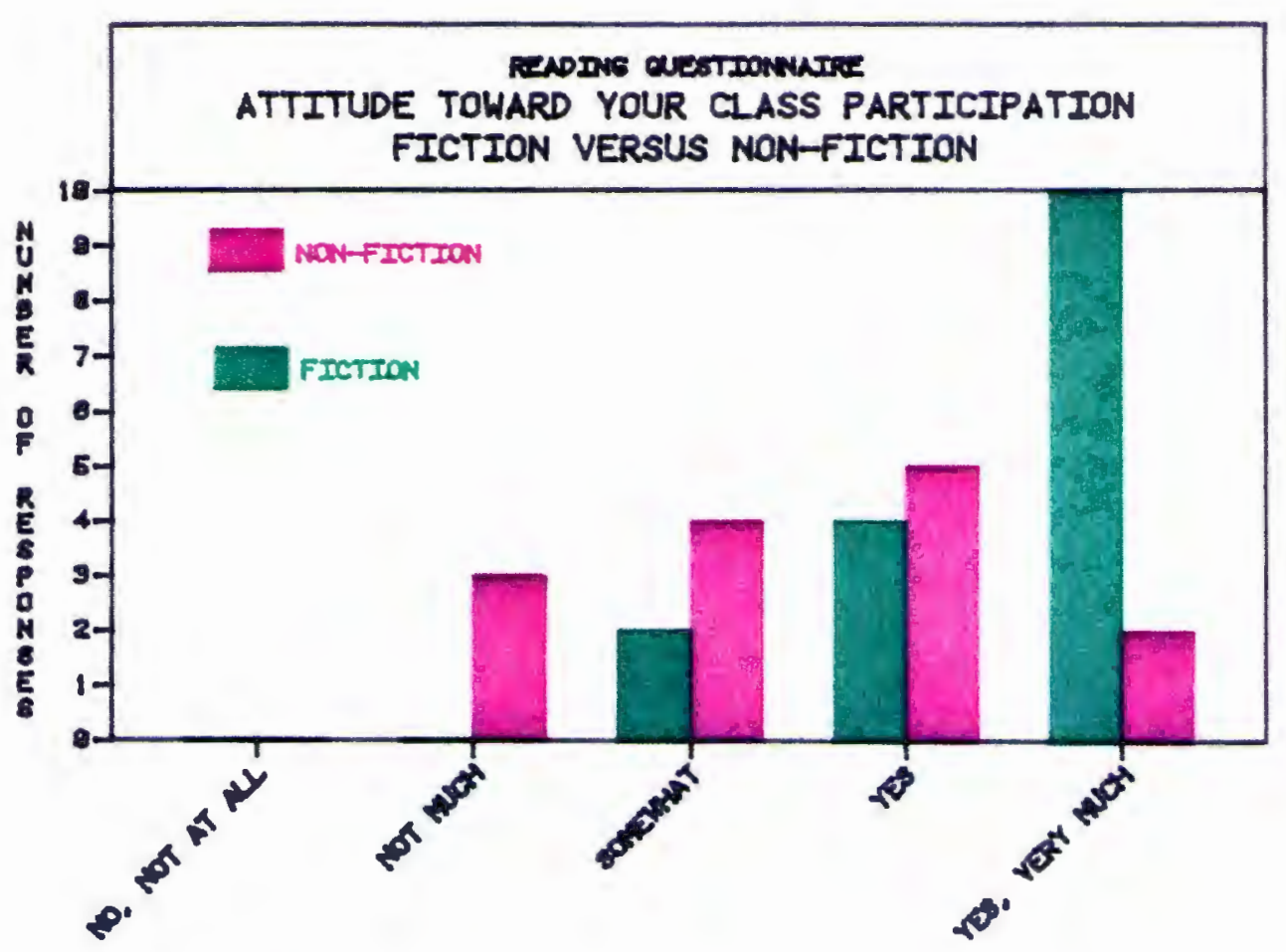

Figure 7. Attitude of fiction and nonfiction groups toward their class participation 
class discussions. Figure 7 shows the specific number of individual responses for each response.

The fifth question asked the students if they found the reading skills taught helpful. The nonfiction group found the skills taught helpful with a mean of 4 while the fiction group was divided between "somewhat" and "yes" with a mean of the differences of 3.5. (see Figure 8). As to the future relevance of the reading material in question six, the nonfiction group with a mean of 4.214 and the fiction group with a mean of 3.875 felt that the reading material would help them in their future classes although the nonfiction group showed a greater conviction, as Figure 9 illustrates.

Question seven attempted to determine if the students felt they had acquired critical reading skills because of the type of reading material used. The response in both groups was extremely close (Figure 10 ) with the nonfiction group mean of 3.7142 and the fiction group mean of 3.6875 . When asked if they felt these reading selections had increased their knowledge of American culture in question eight, again both groups responded very similarly as shown by the means of 3.5 and 3.64 for the fiction and nonfiction group respectively. However, the individual responses in Figure 11 do not seem to indicate this as clearly. The ninth question asked the students if they thought their vocabulary had increased as a result of the reading 


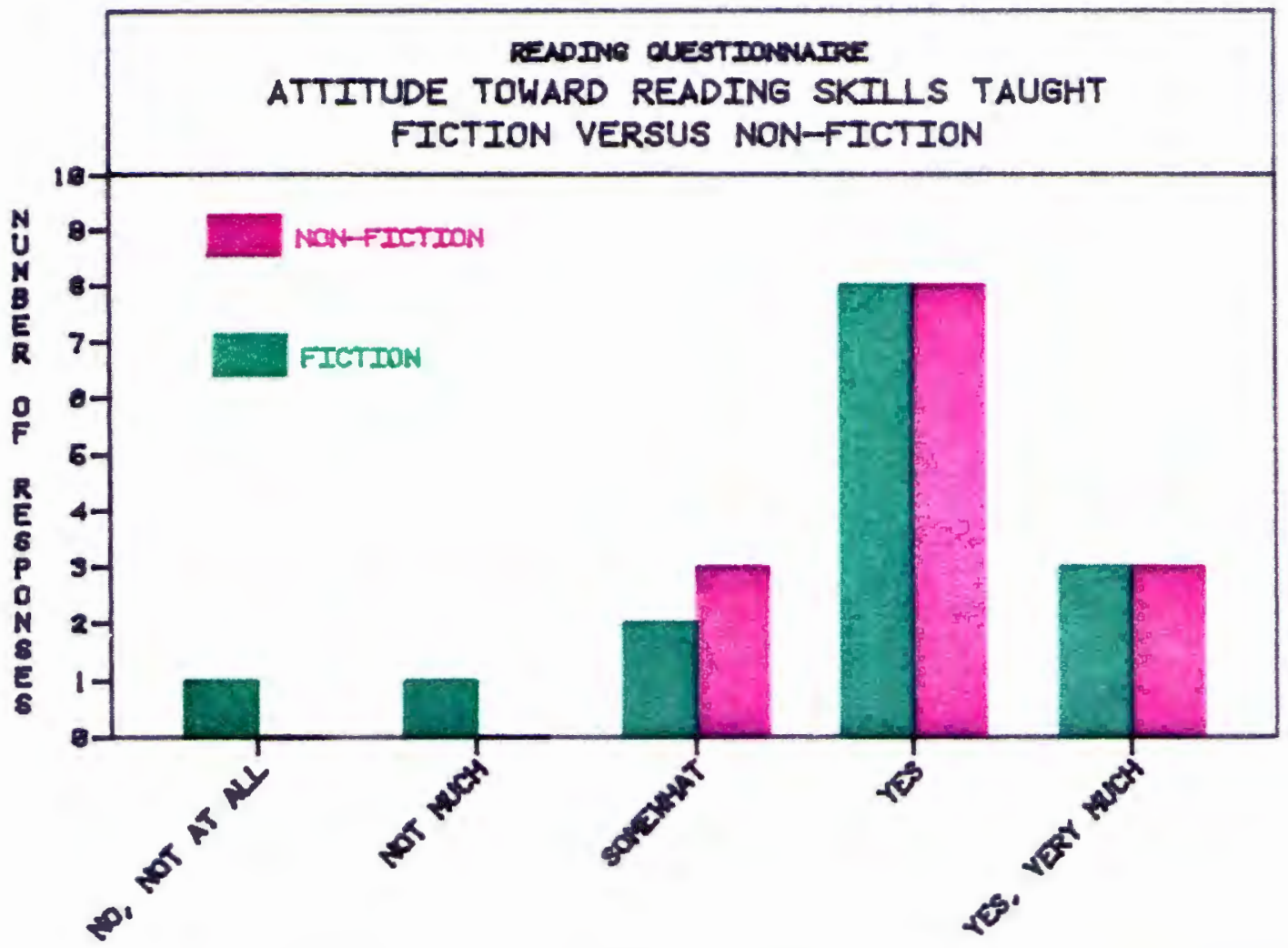

Figure 8. Attitude of fiction and non-fiction groups toward the helpfulness of reading skills taught

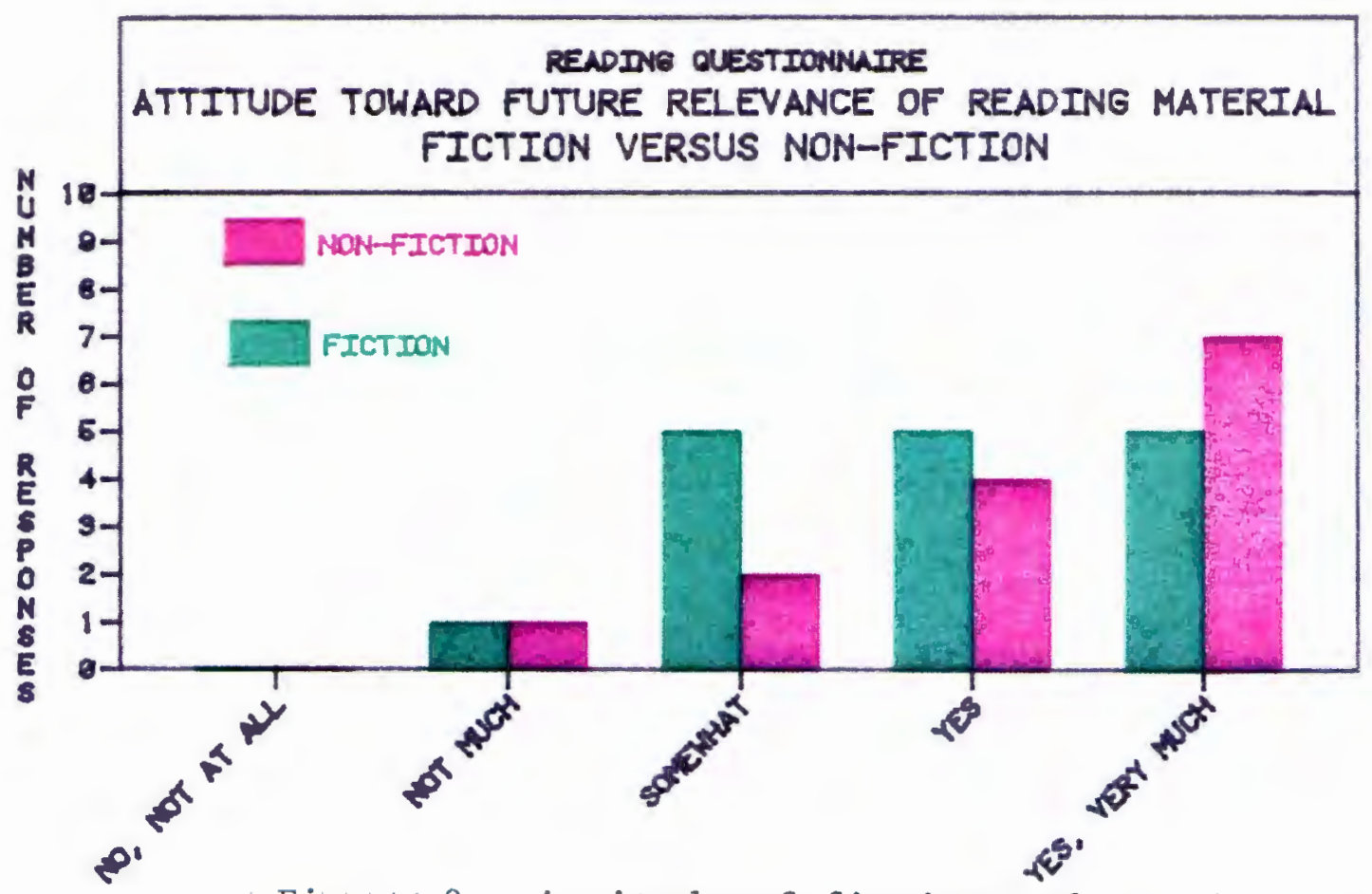

Figure 9. Attitude of fiction and non-fiction groups toward the future relevance of the reading material 


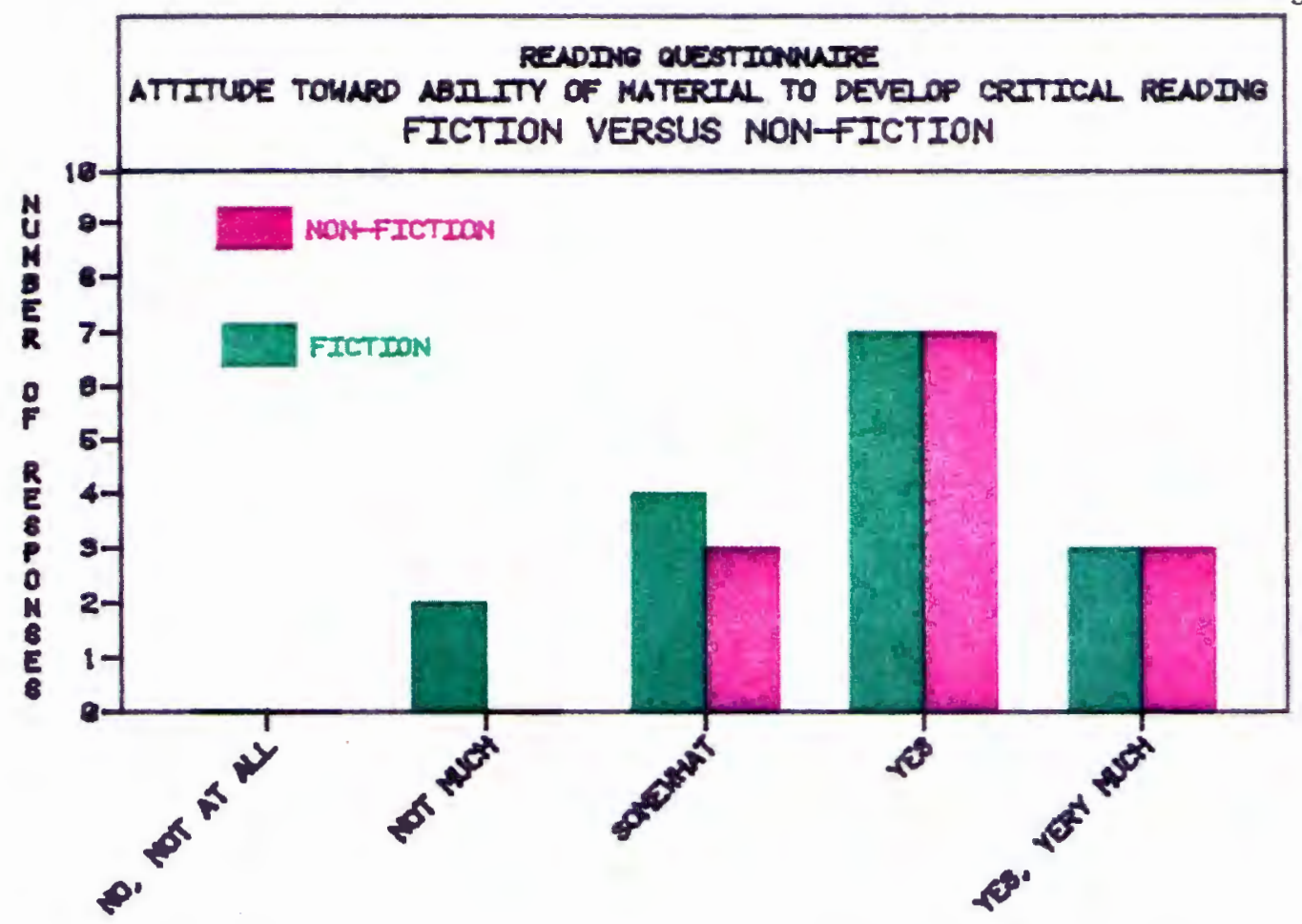

Figure 10. Attitude of fiction and non-

fiction groups toward the reading material's ability to develop critical reading skills

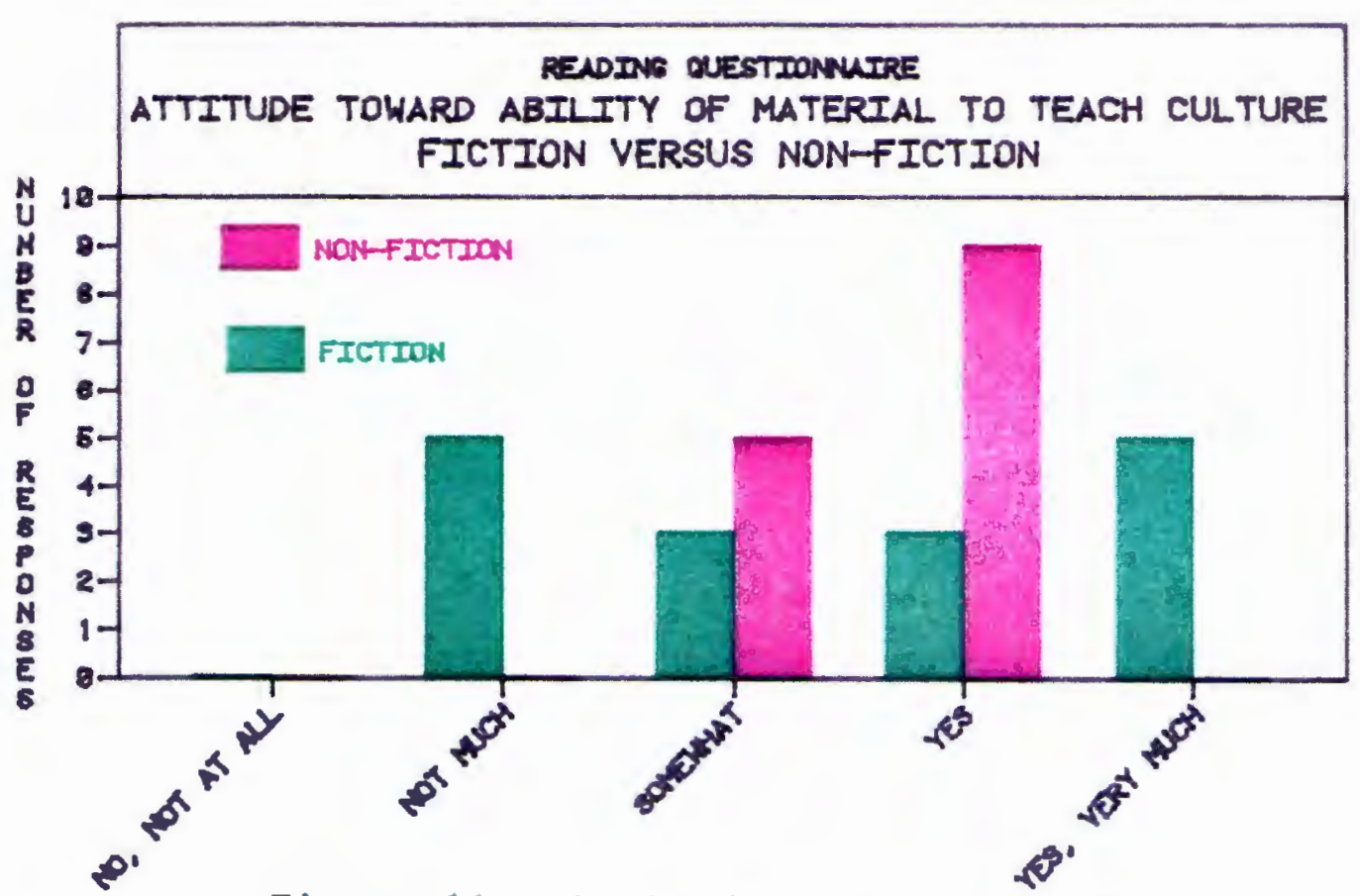

Figure 11. Attitude of fiction and non-

fiction groups toward the reading material's ability to teach American culture 
material. The fiction group leaned toward "yes" with a mean of 3.875 while the nonfiction group leaned toward "somewhat" with a mean of 3.214 , as Figure 12 demonstrates.

Lastly, the students indicated the percentage of their class attendance anywhere from seventy to one hundred percent. In the fiction class, one student attended 708 of the classes, one attended 808 , two attended $90 \%$ and eight attended $100 \%$ of the classes. Conversely, in the nonfiction group, six attended $70 \%$ of classes, one $80 \%$, two $90 \%$ and one $95 \%$ of the classes. (See Figure 13).

\section{Summary}

In order for these results to shed any light on the subject of using nonfiction or fiction in the classroom, they must be interpreted in regards to the four hypotheses presented in Chapter one. If these results do not support the hypotheses than the question of why must be addressed. If, on the other hand, they do support the hypotheses than further understanding as to the debate between fiction and non-fiction in the ESL classroom can be gained. 


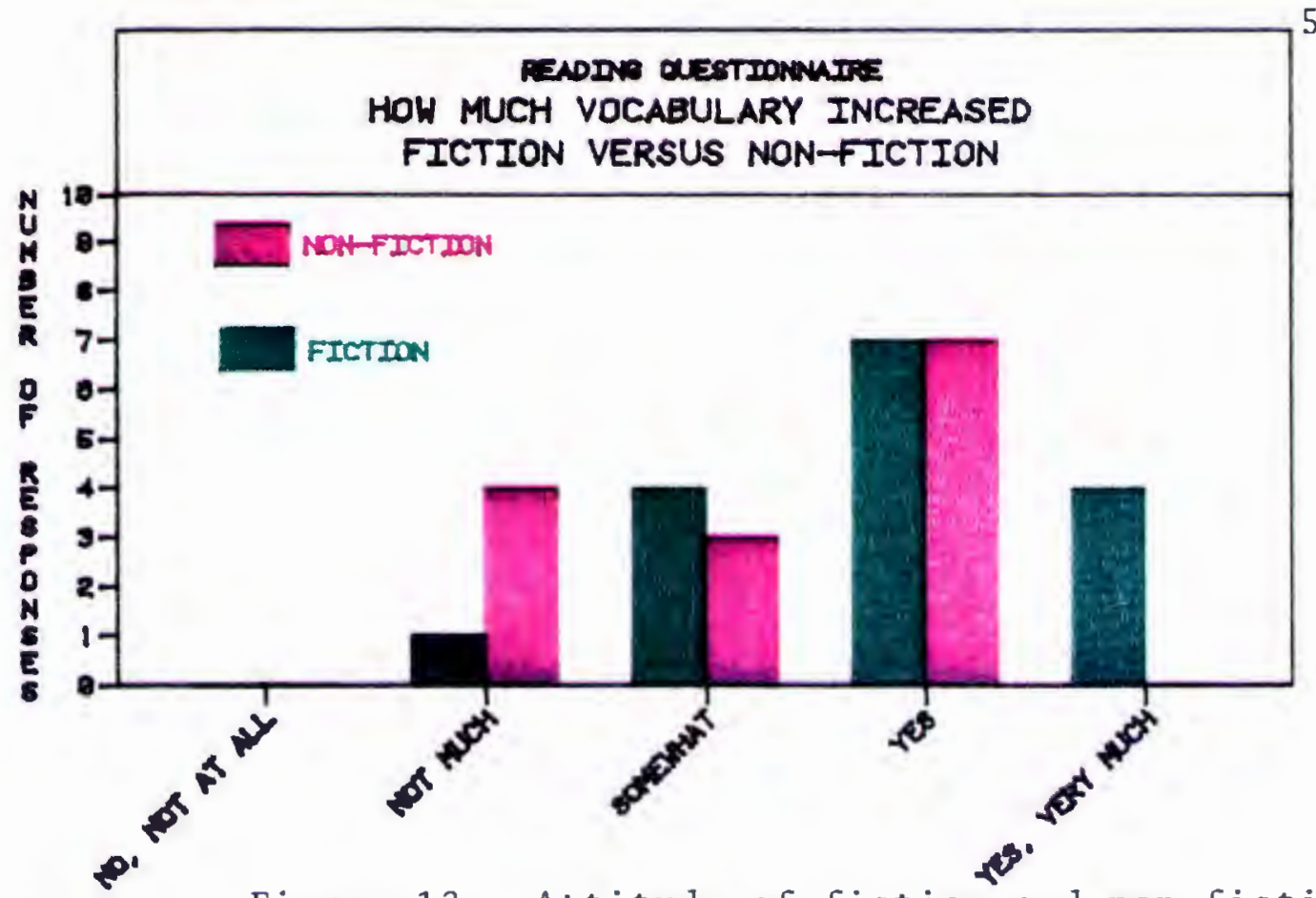

56

Figure 12. Attitude of fiction and non-fiction increased

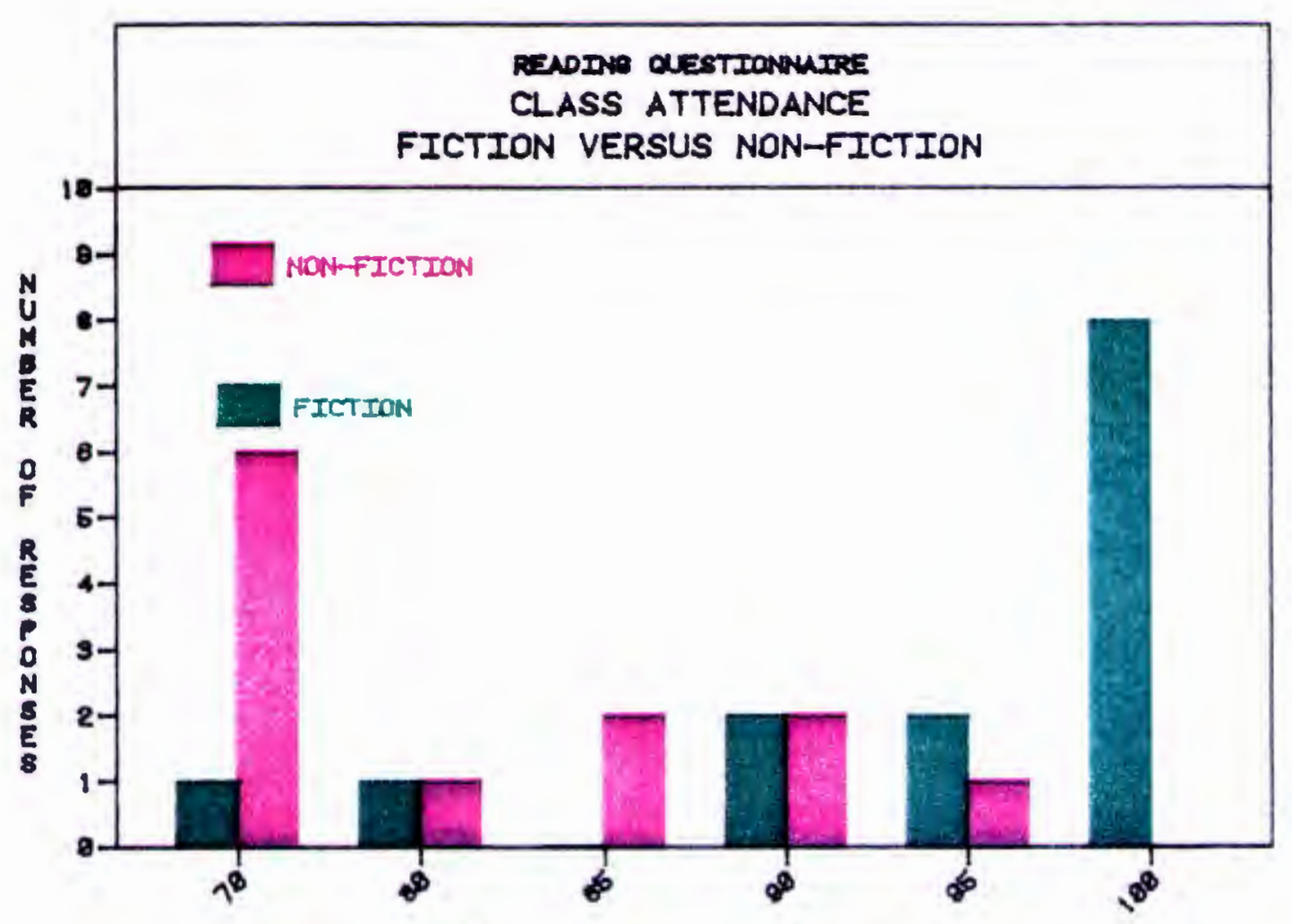

Figure 13. Self evaluation of class attendance by fiction and non-fiction groups 


\section{CHAPTER FIVE}

\section{INTERPRETATION OF RESULTS}

This chapter interprets the various results of the measures used during this study. Although nothing conclusive can be drawn, certain trends are present. Perhaps given a larger sample in regards to overall language proficiency and reading comprehension, significant results would have occurred. And although the questionnaire seems to indicate a slightly greater positive attitude on the part of the fiction group, again the group is too small to draw any solid conclusions. But this study does present some interesting questions which need to be addressed again on a larger scale if we are to determine if literature or nonfiction is better in the ESL classroom.

\section{Interpretation of Cloze Test Results}

The statistical test did not disprove the null hypothesis that students taught with nonfiction would not show a significant improvement over students taught with fiction. In other words, the nonfiction group did not improve significantly over the fiction group in overall language proficiency. As would be hoped with any class, the students in both groups displayea a significant improvement 
in overall language proficiency from the beginning of the class to the end. Upon examining the mean of the differences between the two groups, the nonfiction group exhibited a larger mean of the differences on both the nonfiction and fiction cloze tests which might indicate, given a larger sample, that those taught with nonfiction would show a significant improvement in overall language proficiency over the fiction group. However, due to the small size of this test sample, no definite statement in favor of using nonfiction material in teaching reading for overall language proficiency improvement can be made. Thus, it would seem that using nonfiction or fiction in the classroom makes no significant difference in the student's improvement in overall language proficiency.

\section{Interpretation of Reading Comprehension Test Results}

The statistical results of the study did not support the hypothesis that students taught with nonfiction would show a greater improvement in overall reading comprehension even with all the reading passages in the test being non-fiction. Again, the students in both groups improved significantly from the beginning to the end of each class, but these improvements did not yield any significant results when compared against each other. But in examining the mean of the differences in overall reading comprehension, the fiction group displayed a higher mean of the differences 
by almost a point and a half which, again, might indicate that the fiction group would significantly improve over the nonfiction group given a larger sample. However, this slightly higher mean of the differences might also be caused partially by the greater amount of time the fiction group read English as opposed to the nonfiction group. Perhaps the quantity read contributed to the improvement in overall reading comprehension.

Within the Reading Comprehension test, three different types of questions were employed. The simplest skill -- or the one that requires the least critical reading skill -- is understanding direct statements. In order to understand direct statements, students must be able to restate the reading passage in their own words. More difficult than direct statement questions are those which deal with recognizing main ideas because they require more critical reading skill. Here students must first be able to pick the topic of the reading passage and then determine what is the most general statement being made about that topic. And finally, the type of question which requires the greatest critical reading skill is understanding inferences. This is the ability to imply the meaning of a reading passage although it is not directly stated and involves such skills as assumption drawing.

The fiction group did not show any significant improvement in the area of main ideas. Perhaps this can be 
explained by the fact that fiction passages, usually written as a narrative, do not lend themselves to the usual techniques used in identifying a main idea. For example, in a nonfiction passage a main idea statement can usually be found in either the beginning, middle or end of the paragraph. In a fiction passage, main ideas do not play as crucial a role in understanding as does following the time order of events. And again, since the students had been reading fiction for ten weeks, they were not used to picking the main idea from a nonfiction passage.

However, the fiction group did show significant improvement in the areas of direct statements and inferences. Again, perhaps this improvement in direct statements is due to the fact that fiction (a short story, for example) is a more coherent unit and lends itself to retelling, whereas with nonfiction it is easier to take a section of an article and deal with it in isolation. The fiction group's significant improvement in inferencing seems to support the arguments presented in Chapter Two by scholars who believe that fiction should be taught in the classroom because it develops the deeper critical reading skills.

The nonfiction group showed a significant improvement in the areas of main ideas and inferencing. Again, this improvement in main ideas could be due to the fact stated earlier -- main ideas are much more readily identifiable in 
nonfiction as opposed to fiction and are much more crucial to understanding the passage. The nonfiction group also improved in inferencing as did the fiction group. Thus, the argument that fiction develops more critical reading skills, according to these results, is not supported by these results. However, it should be noted that the mean of the differences for the fiction group was higher than for the nonfiction group in regards to inferencing. This might indicate that those taught fiction had a tendency to improve more in critical reading skills although no significant results were found. In fact, overall the mean of the differences was larger for the fiction group. Again, this might indicate a greater overall improvement for the fiction group though no significant results were obtained.

\section{Interpretation of Classroom Observations}

The observed negative and positive behaviors in the fiction group increased in all observable behaviors from the fourth to the eighth week except talking off task. Thus, the positive behaviors of eye contact, talking on task, reading and writing all increased but so did the negative behavior of eyes downcast or wandering. However, the four highest frequencies during both the fourth and eighth week were reading, eye contact, talking on task and writing, in that order, which are all postive behaviors. So, it can be said from the fourth to the eighth week, the fiction group 
saw generally an improvement in positive behavior.

The nonfiction group from the fourth to the eighth week showed a decrease in eye contact, eyes downcast and wandering and writing, two of which are positive behaviors. On the other hand, the nonfiction group increased in talking on task, talking off task, and reading, two of which are positive behaviors. Therefore, it is hard to determine any significant trend in the group towards positive or negative behavior over a four week period. However, it has been observed from the author's experience with Japanese lof which this class was 95\%) that when they are disinterested or bored, they tend to pretend as though they are reading when in actuality they are not. Thus, what could have been observed as reading perhaps was not. This then could have skewed the results. Again though, the four behaviors with the highest frequencies, in both the fourth and eighth week observations, were reading, eye contact, writing and talking on task, all of which are positive behaviors. Another factor which could have affected the specific behaviors observed is the actual tasks being worked on in class. For example, a discussion of an article would require more talking on task and eye contact while picking out main ideas would involve more reading and writing skills.

In examining the difference in behaviors between the two groups, again, it is difficult to determine that one group displayed a more positive attitude than the other. 
Both groups were very similar in the frequencies of all the behaviors although the nonfiction group displayed a larger frequency of reading. Thus, the hypothesis that students taught with fiction will display a more positive attitude towards reading than students taught with nonfiction as shown by a teacher's observations cannot be supported. Both groups displayed an equally positive attitude.

Since these observed tendencies do not support this hypothesis, and, in fact, both groups displayed very similar behaviors, perhaps it is not the reading material which plays an important role in class attitude as much as it is the teaching style since the same teacher taught both these groups. Another factor which could have influenced these results is the presence of the observer in the classroom causing the students to act in a more positive manner than they normally would.

\section{Interpretation of Reading Questionnaire}

One of the main arguments put forth for teaching fiction is that students will enjoy the reading material more. Question one of the questionnaire solicited responses from the students on how enjoyable they found the reading material. In Figure 4 , the majority of fiction students answered "yes" or "yes, very much" while the nonfiction students were not as unified. Although some answered "yes" and "yes, very much," the choice which received the most 
responses was "somewhat." Although both groups displayed a generally positive attitude toward the reading material, the fiction group, on the whole, displayed a slightly more positive attitude as shown by the means in the two groups thus adding some credibility to the claims of those who advocate using fiction.

Although proponents argue in favor of fiction because it is enjoyable, others argue against it because of the difficulty of the syntax. When the students were asked if they found the language difficult, no conclusive trend could be determined from Figure 5. The fiction group had almost an equal distribution in the responses of "not much," "somewhat" and "yes" whereas the nonfiction group ranged anywhere from "no, not at all" to "yes, very much." Ever though the figure does not seen to indicate any clear response on the part of the students, the means reveal that the nonfiction group found the syntax slightly more difficult than did the fiction group. This then does not support those who argue against using fiction based on the difficulty of syntax.

The students' responses toward the helpfulness of class discussions showed very similar attitudes between the two groups demonstrating a difference in the means of less than four tenths. Besides two nonfiction students who responded with "no, not at all" and "somewhat," all students in both groups responded "yes" or "yes, very much," indicating a 
positive attitude in both groups. Although there were two negative attitude responses in the nonfiction group, this is not enough to substantiate the arguments that fiction students will have a more positive attitude than nonfiction students.

However, the next question does seem to indicate that the fiction students did have a more positive attitude if attitude can be measured by class participation. When asked to evaluate their class participation, the majority of fiction students said they had participated "yes, very much" whereas the nonfiction students were far less decisive, answering anything from "not much" to "yes, very much." Even if attitude cannot be measured by class participation, fiction definitely seemed to encourage much more participation as can be seen with a difference in the means of more than a point.

The students' responses to the helpfulness of the reading skills taught were almost identical in both groups in Figure 8. The majority of students in each group thought that "yes" these skills taught were helpful. These responses again seem to indicate a positive attitude on the part of both groups, with the nonfiction group demonstrating a slightly more positive attitude with a mean of five tenths higher.

Another argument presented in favor of using nonfiction in the classroom is that it will have more relevance for the 
students' future academic careers. The results of the questionnaire seem to support this argument with the majority of the nonfiction students responding "yes" or "yes, very much." The fiction students were not as convinced about the future relevance of their reading material and were equally divided between "somewhat," "yes" and "yes, very much." The mean for the nonfiction group, however, was only slightly higher.

On the other hand, an argument presented in favor of fiction is that it will develop critical reading skills more so than will nonfiction. However, the responses on the questionnaire did not seem to support this. The exact number of students in both groups responded "yes" and "yes, very much" with the remainder of nonfiction students responding "somewhat" and the remainder of fiction students responding "somewhat" or "not much." In fact, such results might indicate that perhaps nonfiction students felt their critical reading skills developed more since none of them responded "not much" while some of the fiction students did.

Again, another argument presented in favor of fiction is that it is an excellent tool for teaching culture. Yet, the results of the questionnaire do not seem to indicate this. The fiction group revealed a wide variety of responses. The majority of the nonfiction group answered "yes" with the rest replying "somewhat." From these results it would seem that students in the nonfiction group where 
more convinced that they had learned American culture from the reading material while the fiction group were divided in their opinion although the mean for the nonfiction group was only approximately one tenth higher. One possible explanation for these results could be the amount of time each group had been in the United states. The fiction group had been in the United States for several years and had thus may have already assimilated American culture. Perhaps this is why they did not feel they had learned much about American culture because they were already familiar with it. The nonfiction group, however, had been in the united states only a few months and consequently knew very little about American culture and therefore felt that the reading selections were helpful in understanding the American culture.

The next question asked the students as to whether they felt their vocabulary had increased. From the responses there was very little difference between the two groups. "Yes" received the largest number of responses in both groups. However, more nonfiction students responded "not much" and "somewhat" than did the fiction students. This, as well as the differences in the means, gives an indication that the fiction group felt their vocabulary had increased more. Again, perhaps this was due to the larger amount of reading which they did.

But perhaps the most telling factor in regards to 
negative and positive attitudes displayed is the students' self evalution of their class attendance. The majority of nonfiction students attended only $70 \%$ of the classes while the majority of the fiction students attended $100 \%$ of the classes. Students who attend class regularly generally are considered more motivated to learn and display a more positive attitude in the class. Also generally, if a class is enjoyable the attendance will be higher. If we can make these assumptions, it appears that the fiction group found their class more enjoyable and therefore found the reading material more enjoyable too since this was the focus of the class.

Thus to sum up the results of the questionnaire, it would seem that on the questions which attempted to measure positive or negative attitude towards the reading material, both groups generally possessed a positive attitude with the fiction group displaying a slightly greater positive attitude in regards to how enjoyable they found the reading material, class participation and class attendance. However, although these results perhaps indicate a trend they are far from conclusive and therefore cannot prove the hypothesis that students taught with fiction would demonstrate a a more positive attitude towards reading than students taught with nonfiction.

Besides attempting to measure attitude, some of the questions on the reading questionnaire addressed the main 
arguments presented by those in favor of using fiction or nonfiction in the ESL classroom. The first of these was how relevant the students felt these selections would be for their future academic careers. These results seem to support the idea that nonfiction bears more relevance for the future than fiction in the eyes of the students. The arguments presented in favor or fiction were far less conclusive. Although advocates of fiction argue that fiction develops more critical reading skills than nonfiction, the responses did not seem to support this. Also, fiction advocates argue that fiction is an excellent source of teaching culture but again, the responses on the questionnaire did not lend support to this argument.

\section{Summary}

Thus, in regards to the four hypotheses presented in Chapter one, the findings of this study do not disprove the null hypothesis of the first hypothesis nor substantiate the rest. Although certain trends can be seen, much further study must be conducted before anything conclusive can be determined. Even though the fiction group did demonstrate a slightly greater positive attitude than did the nonfiction group in the questionnaire, this only indicates a trend and does not offer anything significant. Although the groups improved significantly within themselves in both overall language proficiency and reading comprehension, when 
compared against each other no one group improved more significantly than the other. 


\section{CONCLUSIONS AND RECOMMENDATIONS}

In recent years, the reading skills approach has become the primary method of reading instruction in ESL classes. This method developed from the psycholinguistic theory of reading which views reading as a four-step process -sampling, predicting, testing and confirming -- in which readers use the three cues available to them -graphophonic, syntactic and semantic. The skill of a reader depends upon his/her ability to efficiently use these cues in the reading process. Another aspect of the psycholinguistic theory of reading deals with what is called schema theory. Schema theory refers to the background knowledge a reader brings to the reading selection. If the reader is lacking in background knowledge, he/she will face difficulties in comprehending the passage. Thus, working from this theoretical basis, the reading skills approach attempts to teach the particular reading strategies that a good reader employs such as previewing, skimming, predicting and critical reading to name only a few.

Although the ESL community is in agreement as to the particular method to employ in the classroom, they are far from unified as to the particular reading material -- 
fiction or nonfiction -- to use in teaching the reading skills approach. Until recently, nonfiction remained unchallenged in its use in the ESL classroom. This was due to the fact that in the past the ESL community had been obsessed with form and structure rather than communication. But with the advent of communicative language teaching which advocates using language primarily for communication instead of as an exercise in manipulation, the question of using literature in ESL has again become an issue. Those in favor of using nonfiction argue that literature requires culturally specific background knowledge which a non-native speaker does not possess. They also state that the language found in literature is too complex and difficult for a non-native reader to understand and that it is irrelevant for their future academic careers. The fiction advocates, on the other hand, recognize that the language in literature is difficult but that the problem is not insurmountable. And, rather than allowing the reader's lack of cultural knowledge to be a detriment, they believe that literature is an excellent source for supplying that missing cultural knowledge. But more importantly, the two main arguments fiction advocates put forth relate to fiction's ability to motivate as well as to communicate with the reader. According to communicative language teaching, language's main purpose is to communicate, and literature does just that because it is authentic language. Second, students 
learn better when they enjoy what they are doing and, according to literature advocates, students find reading literature very enjoyable.

Because of this controversy over fiction versus nonfiction, this study was conducted to determine what type of reading material was more appropriate in the ESL classroom. Two separate groups totalling thirty one students were taught the reading skills approach; fifteen read only nonfiction while sixteen read only fiction. Although the two groups demonstrated differences, the difficulty of the reading material required for each group was similar. This study was conducted over a ten-week period in which four hypotheses were tested.

The first, a null hypothesis, suggested that neither group would improve significantly over the other in regards to overall language proficiency as shown by two cloze tests. After examining the results, this was supported even though both groups improved significantly within themselves from the beginning to the end of the study. The second hypothesis proposed that the nonfiction group would improve significantly over the fiction group in reading comprehension since the measure, the Reading Comprehension Test, used nonfiction passages. Once again, both groups improved significantly from the pre- to the post-tests but no one group improved significantly over the other. The thirà hypothesis stated that, based upon a teacher's 
observations of classroom behaviors, the fiction group would display a more positive attitude. Upon analyzing these observations, this hypothesis could not be substantiated. Instead, both groups equally demonstrated predominantly positive attitudes. The final hypothesis proposed that the fiction group would display a more positive attitude than the nonfiction group as shown by a questionnaire. Although the fiction group did display a slightly more positive attitude, it was not substantial enough to clearly support the hypothesis. Besides measuring attitude, the questionnaire also addressed the issues discussed earlier such as difficulty of language syntax, future relevance of the material, ability to teach culture, helpfulness of the reading skills approach, acquisition of critical reading skills and increase in vocabulary.

\section{Conclusions from study}

The significant improvement both groups gained in the areas of overall language proficiency and reading comprehension further endorses the effectiveness of the reading skills approach regardless of whether fiction or nonfiction is used as the reading material. Thus, the ESL community has cause to be encouraged that teaching the specific strategies involved in reading does result in significant reading improvement. However, since this study was not a comparison of reading methods, it cannot be 
determined that the students improved significantly over other methods for teaching reading.

second, the battle in recent years has been against the reintroduction of literature into the ESL classroom because it was considered not as effective as using nonfiction. Even though no one group proved superior over the other in regards to overall language proficiency and reading comprehension improvement, this gives, in effect, some endorsement for using literature in the classroom. Granted literature is no more effective than fiction but it certainly is no worse. Both groups improved significantly in overall language proficiency and reading comprehension not just the nonfiction group. This suggests that readers can improve their skills whether they are taught with fiction or nonfiction. It is true that the fiction group did not show significant improvement on the Reading Comprehension Test in the area of understanding main ideas whereas the nonfiction group did. On the other hand, the nonfiction group did not show significant improvement in understanding direct statements whereas the fiction group did. Thus, no one material was shown to be significantly better than the other.

The last conclusion that can be made from this study is that perhaps student attitude depends not so much on the reading material used as the teaching style employed. Both groups displayed a similarity in the types of behaviors 
observed as well as in the attitude responses given on the questionnaire. This is perhaps due to the teaching style used since the same teacher taught both classes. This could lead to perhaps another study where the students attitudes are tested according to the teaching style employed rather than the material used.

Another possibility for further research that has been raised by this study is determining whether reading quantity plays a role in reading comprehension improvement since the fiction group read a larger quantity of material overall. Also, both the fiction and nonfiction groups were enrolled in very different academic programs, which again could have skewed the results. Further research should also be done to determine if ESL students improve in reading more when they are enrolled strictly in ESL classes or if they are integrated with regular college courses. But, in regards to this study, even though such limitations as lack of random sampling and smallness of numbers hindered the outcome, certain trends are evident. Further research needs to be done on a larger scale to determine if these trends are significant.

\section{Implications for Teaching}

These results suggest that neither fiction nor nonfiction is more effective in the ESL classroom. However, the two materials do display differences. Fiction seems to 
be better for teaching direct statements while nonfiction seems to be better for teaching main ideas. Also, fiction seems to be more enjoyable to read, but students feel nonfiction is more relevant for their future academic careers. Each type of reading material possesses certain advantages. Logically, one would recommend that in conjunction with the reading skills approach, both materials be used together in the ESL classroom. Thus students will receive the advantages of both fiction and nonfiction material. 
REFERENCES

Athey, Irene. (1985) . "Language Models and Reading." Theoretical Models and Processes of Reading. Ed. Harry Singer and Robert B. Ruddell, 3 ed. Newark, New Jersey: Internal Reading Association, 35-62.

Aitken, Kenneth G. (1977). "Using Cloze Procedure as an Overall Language Proficiency Test." TESOL Quarterly. $11: 1,59-67$.

Brumfit, Christopher. (1986). "Reading Skills and the Study of Literature in a Foreign Language." Literature and Language Teaching. Ed. C.J. Brumfit and R.A. Carter. Hong Kong: Oxford University Press, 184-190.

Burke, S.J. and C.J. Brumfit. (1986). "Is Literature Language? Or is Language Literature?" Literature and Language Teaching. Ed. C.J. Brumfit and R.A. Carter. Hong Kong: Oxford University Press, 171-176.

Carrell, Patricia. (1983). "Some Issues in Studying the Role of Schemata, or Background Knowledge, in Second Language Comprehension." Reading in a Foreign Language. 1:2, 81-92.

Carrell, Patricia and John Eisterhold. (1983). "Schema Theory and ESL Reading Pedagogy." TESOL Quarterly. 17:4, 553-573.

Carter, Ronald. (1986). "Linguistic Models, Language, and Literariness: Strategies in the Teaching of Literature to Foreign Students." Literature and Language Teaching. Ed. C.J. Brumfit and R.A. Carter. Hong Kong: Oxford University Press, 110-132.

Clarke, Mark A. and Sandra Silberstein. (1977). "Toward a Realization of Psycholinguistic Principles in the ESL Reading Class." Language Learning. 27:1, 135-153.

Collie, Joanne and Stephen Slater. (1987). Literature in the Language Classroom. New York: Cambridge University Press.

Educational Testing Service. (1985). Guide to the Use of the Descriptive Tests of Language Skills. Princeton, New New Jersey: College Entrance Examination Board. 
Goodman, Kenneth. (1967). "Reading: A Psycholinguistic Guessing Game." Journal of the Reading Specialist. 4, $126-135$.

Goodman, Kenneth. (1973). "Psycholinguistic Universals in the Reading Process." Psycholinguistics and Reading. Ed. Frank Smith. New York: Holt, Rinehart and Winston, 135-142.

Goodman, Yetta, Carolyn Burke and Barry Sherman. (1980). Reading Strategies: Focus on Comprehension. New York: Richard C. Owen Publishers, Inc.

Hill, Jennifer. (1986). Using Literature in Language Teaching. New York: Macmillan Publishers Ltd.

Isaacson, Barbara and Gail Miller. (1985). "Bridges to Sucessful Reading (Reading Skills Lessons for Transitioning LEP Students) and Final Report." ERIC.

Kintsch. W. and E. Greene. (1978). "The Role of CultureSpecific Schemata in Retrieval." Discourse Processes. $1: 1,14-35$.

Long, Michael. (1986). "A Feeling for Language: The Multiple Values of Teaching Literature." Literature and Language Teaching. Ed. C.J. Brumfit and R.A. Carter. Hong Kong: Oxford University Press, 42-59.

McKay, Sandra. (1986). "Literature and Language Teaching". Literature and Language Teaching. Ed. C.J. Brumfit and R.A. Carter. Hong Kong: Oxford University Press, 191-198.

Mikulecky, Beatrice S. (1984). "Reading Skills Instruction in ESL." ERIC.

Rosenshine, Barak. (1980). "Skill Hierarchies in Reading Comprehension." Theoretical Models and Processes of Reading. Ed. Harry Singer and Robert B. Ruddell, 3 ed. Newark, New Jersey: Internal Reading Association, 535-554.

Rumelhart, David. (1980). "Schemata: The Building Blocks of Cognition." Theoretical Models and Processes of Reading. Ed. Harry Singer and Robert B. Ruddell, 3 ed. Newark, New Jersey: Internal Reading Association, 33-58.

Short, Michael H. and Christopher N. Candlin. (1986). "Teaching Study Skills for English Literature." Literature and Language Teaching. Ed. C.J. Brumfit and R.A. Carter Hong Kong: Oxford University Press, 89-109. 
Soule-Susbielles, Nicoles. (1987). "Improving Students" Competence in Foreign Language Reading." ELT Journal. $41: 3,198-203$.

Steffenson, M.S., C. Joag-dev and R.C. Anderson (1979).

"A Cross-Cultural Perspective on Reading Comprehension." Reading Research Quarterly. 15:1, 10-29.

Vorhaus, Renee. (1984). "Strategies for Reading in a second Language." Journal of Reading. 27:5, 412-416.

Widdowson, H.G. (1985). "The Teaching, Learning, and Study of Literature." English in the World. Ed. Randolph Quirk and H.G. Widdowson. New York: Cambridge University Press, $180-194$.

Widdowson, H.G. (1985). Explorations in Applied Linguistics. Hong Kong: Oxford University Press.

Weaver, Constance. (1980). Psycholinguistics and Reading: From Process to Practice. Cambridge, Massachusetts: Winthrop Publishers, Inc. 
APPENDIX A

SAMPLE LESSON PLANS 
SAMPLE ILESSON PLAN ON "SNAKE" by D.H. LAWRENCE

FICTION GROUP

PRE-READING ACTIVITY

1. What is the first word that comes to mind when I say "snake?" (Put their responses on the board and discuss the connotations associated with snakes.)

2. Go through pre-reading questions in literature packet.

READING ACTIVITY

1. Have them read the poem silently several times.

POST-READING ACTIVITY

1. Ask basic information questions.

- Where does this take place?

- When does this take place?

- Who are the characters involved?

- Where do the characters come from?

- What takes place?

2. There are two conflicts or struggles doing on in this poem. One is external. The other is internal. What are they?

3. Internally, what is the man struggling with?

4. What is the man's opinion of the snake? What adjectives does he use to describe how he feels about the snake? The man compares the snake to three different types of people. Who are they? How does this make you feel about the snake?

5. How does the man feel after he throws the log at the snake? Why does he feel this way? What do the last two lines of the poerl mean? 
SAMPLE LESSON PLAN ON "HARLEM" bY L. HUGHES

FICTION GROUP

PRE-READING ACTIVITY

1. What is the history of blacks in the U.S.?

2. What was the Iiving conditions of blacks before the 1960's?

3. What was the Civil Rights Movement?

4. Who was Martin Luther King JI.?

5. How did blacks' I1ves change after 1960 ?

- Explain briefly who Langston Hughes was.

- Read short excerpt from Martin Luther Kins Jr. 's speech.

READING ACTTVITY

1. Have them read the poem several times.

POST-READING ACTIVITY

1. The poem consists of five questions. The flrst question is the basis of the next four. Hughes uses $s i x$ verbs - what are they? What are the five images he links to them?

Thus, six options for a dream deferred.

- dry up

- Iester

- stink

- crust and sugar

- saf

- explode

How does he use the imagery to 11lustrate the many different things which can happen to a dream if it is not realized? 
APPENDIX B

LITERATURE PACKET 
LITERATURE PACKET

TABLE OF CONTENTS

SNAKE by D.H. LaWrence 1

LOVE by J. Stuart 9

THE USE OF FORCE by W.C. W1Iliams 15

THE FILIPINO AND THE DRUNKARD by W. Saroyan 20

I'M A FOOL by S. Anderson 26

THE PARSLEY GARUEN by W. Saroyan 42

RIP VAN WINKIE by W. Irving 56

CRESS LELAHANTY: WINTER by J. West 70

THE' STORY OF AN HOUR by K. ChOpIn 77

THE UNICORN IN THE GARDEN by J. Thurber 83

TULARECITO by J. Steinbeck 89

HARIEM by I. Hughes 103

AIMOS' A MAN by R. Wright, 106

SOUTH OF THE SLOT by J. London 113

THE MAN WITH THE HOE by E. Markham 126

THE DEATH OF THE HIRED MAN by R. Frost 133

THE SECRET LIFE OF WALTER MITTY by J. Thurber 145

MASKS by P. Corneau $\quad 165$ 
APPENDIX C

NONFICTION TEXTBOOK'S TABLE OF CONTENTS 


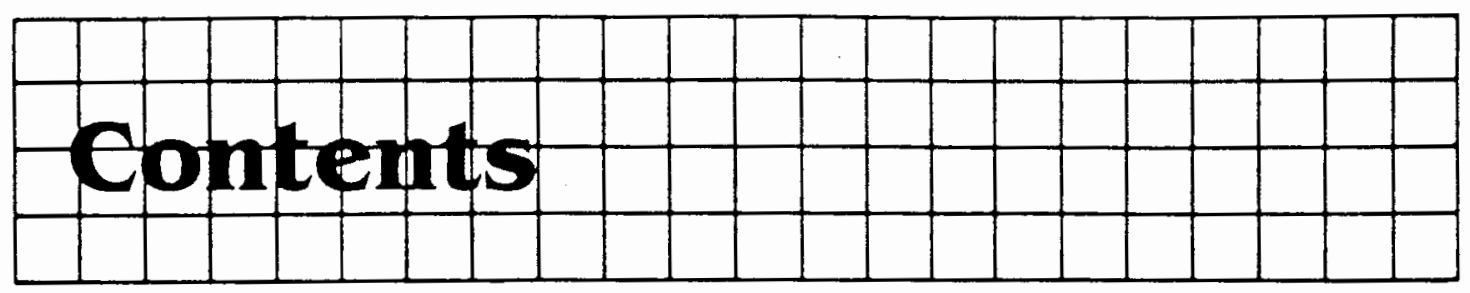

UNIT I

Comprehension Skills $\quad 1$

Introduction 1

\section{ChAPTER 1}

Understanding a Sequence of Ideas

Recognizing Sequence in Narrative Writing 3

Recognizing Sequence Signals 4

Following Directions 6

Understanding Selectivity of Ideas 7

Recognizing Flashbacks 9

Determining Point of View 11

Distinguishing Between a Fact and an Opinion 12

Making Predictions 14

Applying Sequence Skills in Selections 17

"... And, on Shaky Grounds" 17

"The Old-Time Bakery: A Still-Palpable Thrill"

"Welcome Back, Baby!" 30

"Sleep Cycles" 36

Role-Playing 39

\section{ChAPTER 2}

Understanding a Descriptive Listing

Recognizing Listing in Descriptive Writing 41 Identifying Listed Characteristics 42

Recognizing Listing Signals 45

Following Directions 
Identifying Descriptions of Quality, Space, and Sequence $\quad 50$ Applying Fact Opinion and Point of View Skills to

Descriptions 54

Making Generalizations and Assumptions 56

Applying Descriptive Listing Skills in Selections 60

"Spending a Few Days With the Kid that You Once Were" 60

"Prohibition: The 'Noble Experiment' That Failed" 66

"In Praise of Plains" 72

"How to Recognize an Aries" 77

Role-Playing $\mathbf{8 2}$

\section{CHAPTER}

Understanding Comparisons and Contrasts

Recognizing Comparisons and Contrasts in Analytical Writing 84

Recognizing Comparison and Contrast Signals 86

Following Directions 88

Understanding Shared Traits 90

Identifying Comparisons and Contrasts of Parts, Space, and Sequence 94

Applying Prediction and Assumption Skills to Comparisons and Contrasts 96

Applying Fact/Opinion and Point-of-View Skills to Comparisons and Contrasts 99

Applying Comparison and Contrast Skills in Selections 101

"The Feminine Physique" 101

"Leo and Cancer Personalities" 108

"How America Lives" 112

"What is an American" 118

Role-Playing 121

\section{CHAPTER 4}

Understanding Causes and Effects

Recognizing Causes and Effects in Argumentative Writing 123

Recognizing Cause and Effect Signals 125

Following Directions 127

Identifying Causes and Effects and Distinguishing Between

Them 130

Applying Point-of-View Skills to Causes and Effects 134

Drawing Conclusions 137 
Applying Cause and Effect Skills in Selections 143

"On the Pressures and Politics of Waiting in Line" 143

"Cheating" 150

"America in Solitary" 156

"Mind Over Matter" 162

Role-Playing 166

\section{UNIT 【I}

Study Skills

Introduction

\section{CHAPTER 5}

Previewing

Understanding Text Organization

171

Previewing the Textbook

172

Previewing Chapters in Psychology and Sociology

CHAPTER 6

Understanding Topics

185

Identifying Topics of Lists 185

Identifying Topics in Text Paragraphs 187

\section{CHAPTER}

Understanding Main Ideas

Relating Topics, Main Ideas, and Details

Identifying the Main Idea in Various Locations in the

Paragraph

194

\section{ChAPTER 8}

Relating Main Ideas and Details 198 
xiv Contents

\section{CHAPTER 9}

Taking Notes

Understanding Outline Form and the Relationships Among Ideas in an Outline 204

Outlining Lists 206

Outlining Text Passages 209

\section{CHAPTER 10}

Taking Tests

Studying for Exams 217

Learning Approaches to Taking Tests 219

Taking Objective Tests 220

Answering Multiple-Choice Items and Following Directional Words on Tests 220

Answering True-False Items 225

Taking Essay Tests and Following Directional Words 228

\section{UNIT III}

\section{Vocabulary Skills}

CHAPTER 11

Learning Idioms

CHAPTER 12

Using the Dictionary

Using a Word's Part of Speech to Determine Meaning 260

Understanding Multiple Meanings of Words 278

\section{CHAPTER 13}

Using Context Clues

Using Sense-of-the-Sentence Context Clues 294

Using Synonym Context Clues 304

Using Example Context Clues 312

Using Antonym Context Clues 318

Recognizing Stated Definitions $\quad 324$

Index 
APPENDIX D

NONFICTION JOURNAL ASSIGNMENTS 
Journal Assignment \#1

Read "The Importance of Knowing a Second Language" by Dulay, Burt and Krashen and answer the following questions. Do not cogy your answers from the text but answer in your own words.

\section{COMPREHENSION QUESTIONS}

1. What do economic futurists say will be the most sought after skill far business people from the 1980 s an into the trenty-first eentury?

2. According to Craighead's 1930 study, what percentage of U.S. corporation executives who had responsibilities in export development and overseas manufacturing spoke a language other than English? What percentage of the foreign executives in comparable jobs spoke three or more languages?

3. According to the reading, what differences have been found between people who are monoiingual and people who are bilingual or who are polygots?

\section{ANALYSIS AND CONCLUSIONS}

4. In the first paragraph of the article, the authors state that people who live in small countries are required to study at least one foreign language in school. Why is it particularly important for people who live in small countries to be bilingual or multilingual?

5. Imagine a family in which the mother and father each speak a different language and belong to a different culture. What effects might this have on the development of their children?

PERSONAL RESPONSE AND EVALUATION

6. The authors state that people in the United States are in general unconcerned with languages other than English. In your experience, have you found this to be true? If so, why do you think this is the case? 
7. A famous 1 inguist, Benjamin Lee whorf, reported that in the Eskimo language there are ten different wards for snow, depending on whether the snow is falling, has fallen, is soft, or is hard and crusty. One possible explanation for this is that because of their environment the Eskimos observe snow more carefully than people in other countries need to da. Can you suggest any other explanations? Can you think of some ways in which your language differs greatly from English? Are there words that cannot be translated and ideas that are very difficult or impossible to express in English? 
Journal Assignment \#2

Read "The American Male" from the U.S. News and World Report and answer the following questions. Do not copy your answers from the text but answer in your own words.

\section{COMPREHENSION QUESTIONS}

1. "The American Male" describes changes in men's roles in our society. According to the article, what are some of the changes?

2. According to the article, why is there a bachelor boom?

3. What are some of the studies that show that men are adjusting to their role changes?

ANALYSIS AND CONCLUSIONS

4. How has advertising responded to the fact that men are more involved in the home? Which advertisements have you seen that reflect this trend?

5. According to the article, "even the modern tough guy" in the movies "displays a rew sensitivity." Do the movies that you have seen recently seem to support this statement?

PERSONAL RESPONSE AND EVALUATION

6. The article outlines many changes in the relationships between men and women. Do you think these changes are positive or negative? Support your opinions with evidence.

7. Are these changes being felt in other cultures and other parts of the world too? Explain your answer. 
Journal Assignment \#3

Read "Will You Go Out With Me?" from Newsweek and answer the following questions. Do nat copy your answers from the text but answer in your own words.

COMPREHENSION QUESTIONS

1. In paragraph 1, how does Ullman, the author, let the reader know that she is interested in dating her classmate?

2. According to the article, what is the difference between casual dating and formal dating?

3. What is Uliman going to do that makes her very anxious?

4. How has casual dating improved Ullman's social life?

ANALYSIS AND CONCLUSIONS

5. Why dnes Uliman think that men are pleased that women are asking them out?

6. According to Ullman, how has casual dating changed the dating situation in her college?

PERSONAL RESPONSE AND EVALUATION

7. Do you think it is easier for a woman to ask a man for a casual date or a formal date? Explain, using your observations or experiences.

8. Should momen ask men out on dates? Explain, using your observations or experiences. 
Journal Assignment $\# 4$

Read "The High-Priced Call of the Wild" selection from Newsweel: magazine and answer the following questions. Do not copy your enswers from the test but answer in your own words.

\section{COMPREHENSION QUESTIONS}

1. How much money can a person spend in outfitting himself in the new rugged styles?

2. Who started advertising frontier fashions?

3. Describe some particularly popular advertiseménts. List at least three examples.

4. What company's sales have been rising at the rate of $250 \%$ a year?

ANALYSIS AND CONCLUSION

5. Why is this particular fashion 50 popular now?

6. Joseph Margolin, a Washington psychologist, says "Nen are buying a role." What does he mean by that statement? Define the role men are buying.

7. How does this article reinforce the idea (from the Anerican Male articlel that men today are struggling with their identity?

PERSONAL RESPONSE AND EVALUATION

8. Do you think what you wear is a reflection of who you are? Explain.

9. Are fashions important in your country? Why or why not? 
Journal Assignment 45

Read nculture Shock and the Problem of Adjustment in New Cultural Environments" b' Do not cogy your enswers from the text but answer in your own words.

COMPREHENSION QIIESTIONS

1. What is culture shock?

2. What causes culture shock?

3. At which stage does a person reach the crisis point in adjusting to his riew culture? Why?

ANALYSIS AND CONCLUSIONS

4. Explain and describe the four stages of culture shock.

5. What are some of the symptoms of culture shock?

6. What js the honeymoon stage of culture shock and how lons does it last?

PERSONAL RESPONSE AND EVALUATION

7. Do you agree with the author's explanation of culture shock? Do you find it exaggerated? Accurate? Incomplete?

8. When you came to the U.5. did you experience culture shock? What particular symptoms do you experience? 
Journal Assignment \#6

Read the Language and Thought selection which includes "Helen's Awakening to Language by Helen Keller and answer the following questions. Do riot eopy your answers from the text but answer in your own words.

COMPREHENSION QUESTIONS

1. Who was Helen Keller?

2. What words did Helen first learn to spell? Did she know what these words meant?

3. What happened to Helen's new doll? Why did it happeri? How did Helen feel immediately after it happened?

ANALYSIS AND CONCLUSIONS

4. How did Helen discover that words represent things?

5. How did the discovery of language change Helen?

6. Explain what the following quote means: "Without words, her mind was starved and empty. With them, she could' see' and learn." How does this statement sum up the reading selection?

PERSONAL RESPONSE AND EVALUATION

7. How is what Helen experienced in discovering similar to learning a second language? Has your learning a new languaje opened your mind to thinking about the world in a new way?

8. In trying to learn English, have you experienced some of the same teelings Helen did? If 50 , which ones and why? 
Journal Assignment \#>

Read "Motherly and Fatherly Love" by Erich Fromm arid answer the following questions. Do not copy your enswers from the text but answer in your own words.

COMPREHENSION QUESTIONS

1. What is the basic difference between motherly and fatherly love?

2. What has happened to the mother and father figures by the time a person is mature?

3. Why does a person need both a fatherly and motherly conscience?

ANALYSIS AND CONCLUSIONS

4. As Fromm sees it, what are the characteristics of motherly love? Functions? Advantages? Disadvaritages?

5. As Fromm sees it, what are the characteristics of fatherly love? Functions? Advantages? Disadvantages?

6. How does Fromm account for the difference between inotherly and fatherly love? In what does each originate?

PERSONAL RESPONSE AND EVALUATION

7. What is your opinion of Fromm's defintions of motherly and fatherly love? (Notice that he has said that these terms refer to "ideal types", principles not necessarily to every mother and every father. Either parent could be capable of either type of love; one person may be capable of both kinds.) How close does he come to your own experience?

8. Do you fesl Fromm's definitions depend on a given culture or are they universal? Explain. 
Journal Assignment \#8

Read "Jobs of the 19905" by Gwen Kinkead and answer the following questions. Do no copy your answers from the text but answer in your own words.

\section{COMPREHENSION QUESTIONS}

1. What jobs will open up in the high-tech fields in the 1990s?

2. What occupation will provide the greatest number of jobs? How will this job change?

3. According to the article, what do occupational therapists do?

ANALYSIS AND CONCLUSIONS

4. This article is about jobs that will be available in the 19905 in the United States. If you were to write a similar article about your country, what jobs do you thirk would be the most available?

5. The proportion of older people in the United states population is increasing. Today approximately $11 \%$ of the population is sixty-five or over, and it is predicted that $21 \%$ of the population will be $5 j x t y-f i v e$ or older by the year 2030 . Is there $a$

connection between the aging population and the kinds of jobs that will be available? Can you think of jobs that will be needed to service the sixty-five-and-over age group?

6. According to the article, the 1990 will provide the greatest number of jobs for secretaries. Why do you think this need for secretaries will exist? Do you think there will be an increased demand for bilingual secretaries? If 50, why?

PERSQNAL RESPONSE AND EVALUIATION

7. Did this article arouse your interest in any occupation that you hadn't thought about before? What made it sound interesting to you? 
8. What aspects do you consider when deciding on a field in which to major and work in the future? What factors are most important to you? 
Journal Assignment \#9

Read "Biological Differences" by Alexander Alland and answer the following questions. Do not copy your answers from the text but answer in your own words.

COMPREHENSION QUESTIONS

1. Alland compares men and women. According to the article, in what ways is man superior to woman?

2. In what ways is woman superior to man?

3. Alland makes a comparison between birds and human beirigs. What is the major difference that species selection has produced in the bird world?

ANALYSIS AND CONCLLISION

4. Can you think of any reason why a woman's hearing especially at the upper range of the scale, the higher pitches of sound, might be better than a man's? Why would a woman need this ability?

5. Why does Alland believe that men are more expendable than women?

6. Why are men physically stronger than women? What purpose does men's strength serve in society as we know it?

PERSONAL RESPONSE AND EVALUATION

7. In almost all societies, women live longer than men. Why do you think this is so?

3. Are boy babies treated differently thana girl babies?

Describe some differences in treatment that you have observed. keep in mind the colors that babies are dressed in, the toys they are given, how much they are held, and how they are played with. 
9. Do you think babies of different sexes should be brought up differently? Explain your point of view with your observations and experiences. 
APPENDIX E

FICTION CLOZE TESTS 


\section{FICTION CLOZE PRE-TEST}

Once upon a time there was a young man named Arlstotle Spinoza who wanted to save the human race. So he dropped out.

- Cleaniless is overrated." sald Arlstotle to

- Sorlal taboos against long halr are

It's hate, greed and striving that the world. The human race will be saved until we all come love each other."

So he gave baths, grew his halr long and

to live in a hippie pad. away, Aristotle ran into

several minor and one major one. The minor

included underarm offensiveness, an ltchy neck chronic Indlgestion. The major one was , try as he might, he couldn't himself to love everybody - particularly one roommate given to playing the sitar 2 a.m. and eating crackers in bed. took his problems to a guru. ," said the guru, "how many mierograms acid are you taking?

"AC1d?" asked

- Lysergle acid. LSD. It will Increase awareness, expand your conselousness, and you love everybody." sald the guru solemnly. 250 micrograms twice weekly four hours eating. Next."

And it worked: After LSD, Arlstotle saw pretty colors, heard sounds, smelled pretty smells, felt pretty and loved everybody. He even equated 
Beethoven's Fifth Symphany. But these wore off in elght hours. And of the time he itched, smelled, and couldn't stand sitar music.

-LSD_fine, but it isn't perfect," he thoughtfully. What the human race needs The Perfect

Pi11."

After many an , he invented it. The Perfect Pill contained itch reliever, a deodorant, an antacid. and, unlike LSD, it turned you on permanently. Pertect P111 was an instant__ Soon everyone In the world was turned on __. Hate, greed, striving and silly social taboos__. Everybody sat around seeing pretty colors, ___ to pretty sounds, smelling pretty smel 1s, pretty teelings and loving each other. course, while no one bothered to to war anymore, no one bothered build bridges, have children or explore universe anymore, either. And atter a hundred years of sitting around loving other

the human race died off. was replaced by the

three-toed sloth, gentle creature. "It's your bag now, * the last man to the three-toed

- But

I notice you don't take Have you found a better way love each other?"

"Naturally," sald the three-toed sloth.

Moral: If the only way people can be induced to love one another Is through ingesting chemicals the human race deserves what it gets. 
FICTION CLOZE POST-TEST

once upon a time there was a little boy named sam. He was a good little boy and did almost everything his father told him to do. When his father said, "Brush your teeth," he brushed his teeth. When his fether said, "Eat your rutabaga," he ate rlitabaga. frid so forth. Each time did what

his father said, his was very, very happy. As for Sam, liked making his father happy. he never dad

learn to care for rutabaga.

of course, like most boys, Sam sometimes didn't do. what was told

Once he chewed gum school.

Once he went swimming in abandoned quarry. And once he rode bieycle in the street.

Al1 of he

enjayed much more than eating - Each time Sam's father heard of transgressions, he would look up from bills and say, "Dammit, you must more

respect for authority." When Sam why, his father would snap, "Because say so." Or, "Shut up and

your rutabaga."

Determined to learn why should respect autriority, Sam went to greatest university in the whole wide

It had lots and lots of The Regents, the President, the Chenceldor a.l the Dearis were for authority. faculty wrote long dissertations on "The of Authority in a. Free Society," problem 
they examined minutely from every

angle. But the

students, of course, against authority. They were for freedom. ." cried sam, "is much better thari autboritg!" joiried the Free Speech Movement, the EEx

League, and cadged free iunches possible. He wrote free verse, practicec love, and passed out ariarchist pamphlets his free time. He grew a because the authorities didn't like beards, wore sandals because the authorities didn't sandals. Sometimes he didn't brush his for two days runnirig and he never, never to eat another rutabaga long as he lived. He was very happy.

The authorities, of course, "Dammit, you must

learn more respect authority." But Sam didn't care because was happy ard he liked freedom And

his girl friend, Nellie Jo, - They agreed on

everything. In tact, Sam graduated, they agreed to get - Sam got a job to support and bought a

house for them live in and an electric toothorush brush their teeth with. Ir time, sam Jurior came

alaoris. he was a good little boy did almost

everything his father told to do. Which made his

father - very happy

didn't do what he was told. When this happened aan would look up from his bilis and s3y, "Dammit, yod've got to learri more respect for authority." 
Moral: This is truly the best of all possible worlds. The yourig like freedom and the old like authority. Thus each of us is happy with what he's got. 
APPENDIX F

NONFICTION CLOZE TESTS 
NON-FICTION CLOLE PRE-TEST

You get the holiday snapshots back and there's a wonderful phota of Mom... except the way you lined it up, the Christmas tree appears to grow directly out of her head. Usually, you'd be stuck with your surreal snap. But if you're willing to convert the botched portrait to black and white, you can now fire up your personal computer, press some keys - and remove that errant tree electronically. While you're at it, take out tew of Mom's wrinkles; no one ever know. The trick:

electronic photography, mix of computers and cameras

that Ultimately have as big an impact

shutterbugs as George Eastman's first Kodak.

Conventional uses chemicals that permanently record the on a negative or slide. The way to remove a stray Christmas is through tricky darkroom work or hand retouching. Electronic photography, by eontrast, images on computer discs as digital

Information, is easy to manipulate. For several - magazines and ad agencies have used

machines to manipulate photos electronically, but the technology has reached personal computers. programs with names 11 ke Snapshot and ImageShot computerists put black-and-white photographs on screen modify them with electronic versions of retouching techniques. "The

personal computer," says Mikkel Aaland, computer columnist 
electronic darkroom.

How does the photograph

into the computer in the first ? Usually via a scanner,

a \$2,500 gadget

looks like a small photocopier. Instead

copying a photo, however, the scanner the thousands of picture details into digital ones and zeros a computer The computer can then reconstruct the on its screen and retain it its memory. Once the picture is "digitized," can be altered simply by ipstructing computer to change its ones and a rank amateur cari, mouse to move an on-screen pointer, unsightly telephone poles from a country for example, - The program will automatically duplicate sky, or trees from elsswhere in the and then fill

in the areas the poles once stood. "It's much

than hand retouching," says New York

computer consultant Bert Monroy. "What used take a week can be done a marning."

For now, electronic photography pricey: equipping a computer with a scanner software could cost $\$ 3,000 ;$ a suitable frinter, \$3,500 more. Prices are dropping but professional are already happily paying the tab. Ft. worth Bob Lukeman and Gordon Blocker used

Apple computer to produce a photograph billboards in a local United Way Monroy now does all-electronie advertising layouts: a photographer takes pictures using a video camera. The video images are transmitted over the telephone 
directly into Monroy's computer. 


\section{NON-FICTION CLOZE POST-TEST}

For now, electronic photography is pricey: equipping a computer with a scanner and software could cost $\$ 3,000 ;$ a suitable printer, \$3,500 or more. Prices are dropping but professional photographers are already happily paying the tab. Ft. Worth photographers Bob Lukeman and Gordon Blocker used an Apple computer to produce a photograph for billboards in a local unjted Way campaign. Monroy now does all-electronic advertising layouts; a photographer takes pictures using a video camera. The video images are transmitted over the telephone directly into Monroy's computer. "Within minutes of the shooting," says Monroy, "I've already retouched the picture and printed it out."

Electronic photography is also a breakthrough desktop publishers, who use personal computers laser printers to produce everything from to full-length books. Until now, putting in, say, an illustrated brochure has difficult. After preparing the brochure's text a computer, the desktop publisher would

to take traditional paper photographs and paste them alongside the text. Now can be taken from a scanner a video camera, processed by the and electronically mixed in with the The entire brochure--text plus photos-be printed out at one with no eutting or pasting. 
enter the electronic still camera, which the need for a scanner by color images right onto floppy discs. disc holds 50 images and the can be displayed on any television computer. At the 1984 olympics in Los Angeles, Japanese photographer used such a and sent his digital pictures Tokyo by telephone, where they appeared newspapers only nours later. While exciting, experiment hasn't

revolutionized photojournalism for two Conventional film still produces sharper although the elctronic prints are close to the quality of some

films. For another, the future isn't : the first such camera on sale the United States costs $\$ 2,725$. But half dozen manufacturers plan to produce still cameras in the next year, at least one will cost under $\$ 1,000$. the mid-9905, the Japanese expect to several million electronic cameras a year. camera of the future will probably into the TV set and offer same retouching features as the current

programs. Amateur photographers will show their on television and use a small printer to produce high-quality prints their favorite shots. Some experts even that hobbyists will employ photography's gift recording reality to make their fantasies true--it would be easy to their own images, for 
of a bodybuilder or surrounded by on the deck of a palatial yacht. So much for the notion that the eamera never lies. Just imagine the picture Christmas card of the future: "It's been quite a year for our brood. Here we are with the kids, in front of our new home at 1600 Pennsylvania Avenue..." 
APPENDIX G

CLASSROOM OBSERVATION SAMPLE CODING SHEET 


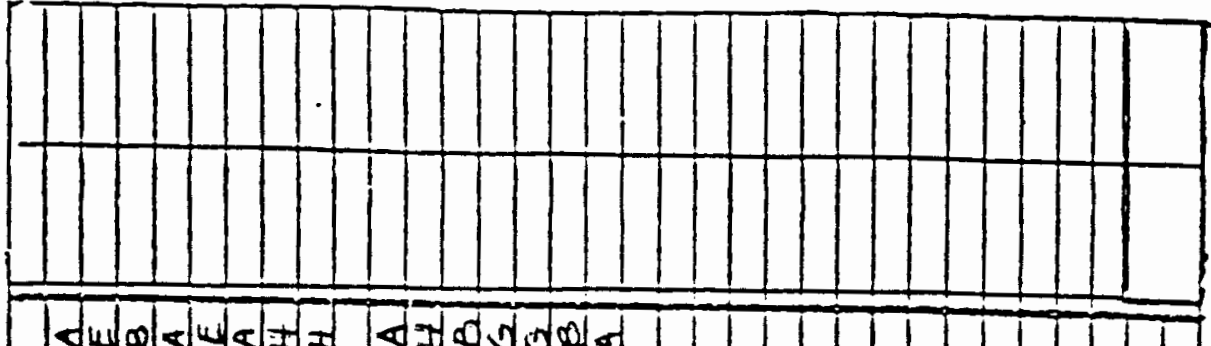

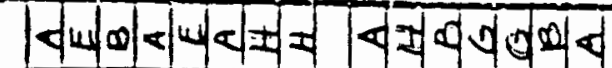

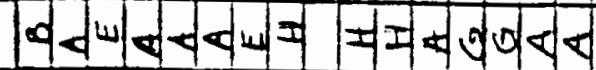

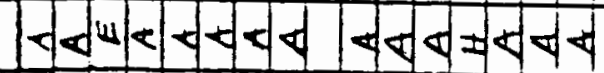

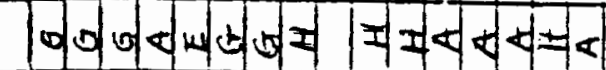

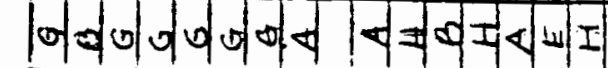

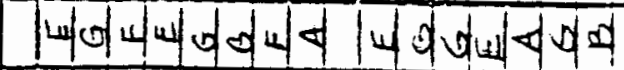

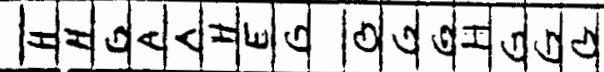

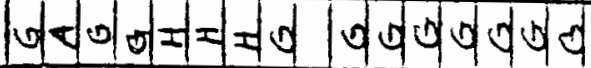

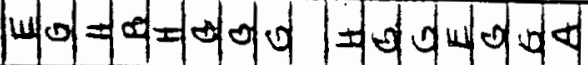

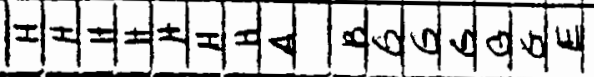

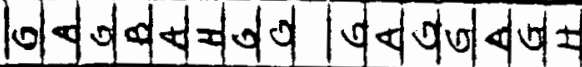

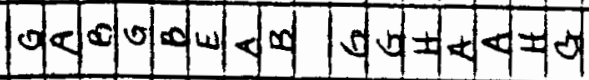

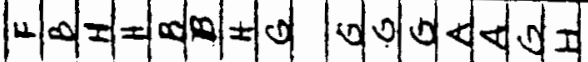

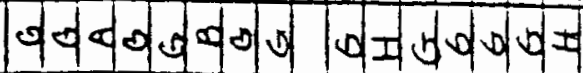

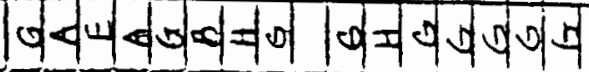

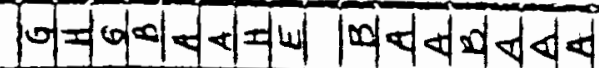

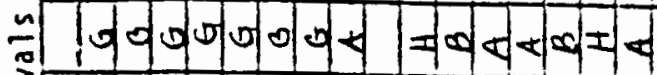

$\underset{⿱ 亠 幺}{\vdots}$

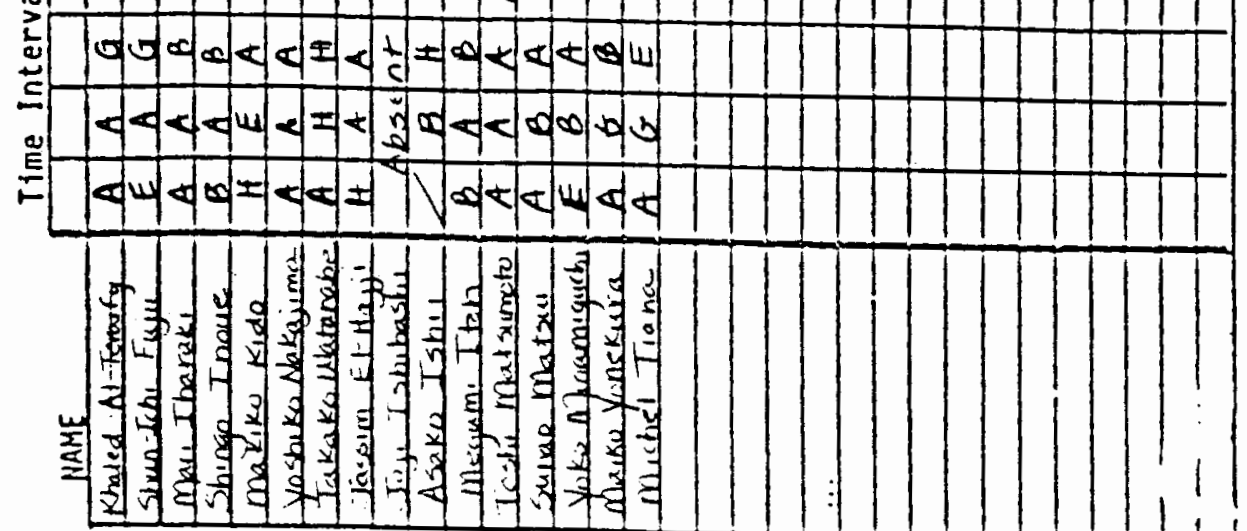

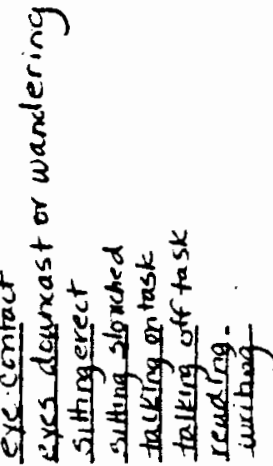

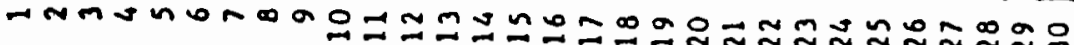

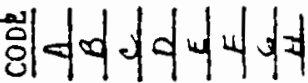

